\title{
FLUORESCENT CARBON DIOXIDE INDICATORS
}

\author{
Andrew Mills* and Stephanie Hodgen
}

\section{INTRODUCTION}

There are few analytes in the world as significant as carbon dioxide, equal, as it is, in importance as oxygen and $\mathrm{pH}$. Carbon dioxide is a basic chemical feedstock of life, which when coupled with green plant photosynthesis ${ }^{1}$, i.e.

$$
\mathrm{CO}_{2}+\mathrm{H}_{2} \mathrm{O} \stackrel{\text { sunlight }}{\longrightarrow} \mathrm{C}\left(\mathrm{H}_{2} \mathrm{O}\right)+\mathrm{O}_{2}
$$

where $\mathrm{C}\left(\mathrm{H}_{2} \mathrm{O}\right)$ is a reduced form of carbon such as a sugar or starch, generates the fuel and food necessary for the continued existence of most known forms of life. The reverse of reaction (1) is the basis of most cell metabolism, releasing, as it does, the energy for life. Thus, not only is carbon dioxide usually an essential ingredient to make the prerequisite chemicals for life, it is also often used as an indicator of the existence of life and a measure of health. For example, in medicine, the key, basic analytes that are routinely monitored in the blood of hospital patients are: dissolved oxygen, $\mathrm{pH}$ and carbon dioxide ${ }^{2}$. In clinical chemistry, a whole area devoted to the monitoring of the levels of carbon dioxide in breath has emerged, i.e. capnography, in which not only the level of carbon dioxide is important, but also its temporal variation, since both provide valuable medical diagnostic information ${ }^{3}$.

The use, presence and measurement of carbon dioxide is also important in many industries. For example, in many biotechnology industries the measurement of carbon dioxide levels forms an important part of process control. Nowhere is this more important than in the brewing industry, where the continuous monitoring of carbon dioxide levels during the fermentation process is vital for: high product yields, minimal unwanted, and not very tasty, by-products, and an optimized control strategy ${ }^{4}$.

In the food industry, a revolution in food packaging has come about through the use of carbon dioxide in modified atmosphere packaging (MAP) ${ }^{5}$. In MAP the food package is flushed with an oxygen-free gas, usually carbon dioxide, before being sealed and sent off to the wholesale or retail trader. By gas flushing the food package in this way,

\footnotetext{
* Andrew Mills and Stephanie Hodgen, Department of Pure and Applied Chemistry, University of Strathclyde, Glasgow, G1 1XL, UK
} 
oxygen is removed and, as a consequence, aerobic spoilage microbes cannot thrive. As a result, the food contained within a MAPed package will keep typically 3-4 times longer,

without recourse to chemical preservatives, which are becoming increasingly unacceptable to the consumer. This form of packaging is now routinely used in the packaging of a wide variety of foods, including: bread, biscuits, cakes, pastries, nuts, sweets, coffee, tea, wholefat, dry foods, processed, smoked and cured meats, dairy products, fresh and pre-cooked pasta and noodles and pet food, to name but a few ${ }^{5}$. Carbon dioxide is commonly used as the flush gas in MAP, mainly because it is plentiful $\left(0.03 \%\right.$ of air is carbon dioxide), easily liquefied (critical temperature $=31^{\circ} \mathrm{C}$, critical pressure $=72.9 \mathrm{~atm}$ ) and, therefore, inexpensive. In addition, high levels of carbon dioxide have an antimicrobial action by reducing the rate of microbe metabolism even if oxygen is present ${ }^{5}$. As a consequence of its use in MAP the detection and measurement of carbon dioxide is very important in the food packaging industry.

Because of its low critical temperature and pressure, and chemical inert nature, carbon dioxide also features strongly in the use of supercritical fluids to dissolve and extract substances, most notably caffeine from coffee beans to generated decaffeinated coffee. Thus, in many industries, the use, or presence, of carbon dioxide is commonplace and its measurement and continuous monitoring often essential.

The measurement of carbon dioxide levels is also an important feature of environmental monitoring, providing, as it does, a rough gauge of the health of the environment under test. Thus, stagnant lakes and rivers are often characterized by high levels of dissolved carbon dioxide. The levels of carbon dioxide in our atmosphere are routinely monitored worldwide by environmentalists interested in the greenhouse effect of this gas on the Earth's delicately balanced biosphere ${ }^{6}$. The major source of carbon dioxide in the biosphere is combustion, generated by industry, domestic heating, burning, biomass degradation and fermentation. Knowledge of the levels of carbon dioxide in the atmosphere is obviously important, but just as important, if not more so, is that of the levels of carbon dioxide in the oceans, since these contain $60 \%$ more carbon dioxide than in the atmosphere! The oceans, by acting as a vast carbon dioxide reservoir, help reduce the effect of carbon dioxide as a greenhouse gas and so lower the potential of global warming $^{6}$. Monitoring the levels of carbon dioxide in the atmosphere and hydrosphere is particularly important since they are not in equilibrium with each other and the rate of exchange between the two, which is so very important to the continued existence of life on this planet, depends on a wide variety of parameters including: atmospheric pressure, wind, humidity and temperature.

The quantitative and qualitative analysis of carbon dioxide in the gas phase is often routinely carried out using infra-red spectroscopy. However, the latter is prone to interference and requires long path lengths, and bulky and expensive equipment which lacks mechanical stability. Gas phase measurements of carbon dioxide are also often carried out by gas chromatography, usually using a molecular sieve column and a thermal conductivity detector. However, such instrumentation is expensive and usually requires a trained technician for its routine operation and maintenance. The measurement of dissolved carbon dioxide in an aqueous medium (e.g. riverwater, salt water or blood) via infrared spectroscopy or gas chromatography is more difficult and other analytical methods are preferred. Thus, the routine monitoring of carbon dioxide, especially dissolved carbon dioxide, is currently dominated by the Severinghaus electrode; an analytical device that has been in regular use for nearly 50 years without 
serious challenge $\mathrm{e}^{7,8}$. This electrode utilises a $\mathrm{pH}$ electrode, placed in contact with a thin layer of an aqueous sodium bicarbonate solution, trapped behind a gas-permeable,

ion-impermeable membrane. Carbon dioxide in the test medium diffuses through the gas-permeable membrane and causes a change in the $\mathrm{pH}$ of the trapped bicarbonate layer that is measured by the $\mathrm{pH}$ electrode. The key equilibria associated with this process are reported a little later in this article and, as we shall see, these equilibria allow the measured $\mathrm{pH}$ to be simply related to the partial pressure of carbon dioxide, $\mathrm{P}_{\mathrm{CO} 2}$, in the test medium. Unfortunately, the Severinghaus electrode is bulky, quite expensive, prone to electrical interference, affected by acidic or basic gases, and exhibits slow response and recovery times. Other problems include: effects of osmotic pressure (caused by variable salt conditions in the test sample), reference electrode contamination and liquid junction fouling. These electrodes are also quite expensive, usually quite delicate, and require high and regular maintenance. Finally, the Severinghaus electrode does not have a disposable transducer.

In recent years there has been a growing interest in the development of optical sensors for a wide variety of analytes ${ }^{9-16}$. Such sensors are usually sensitive, robust, rapid-in-response, inexpensive, easily miniaturised and do have a disposable transducer. In addition, through fibre optics, optical sensors offer the possibility of remote, continuous, multianalyte analysis in low volume locations, such as the artery of a premature baby. Optical sensors are usually either colourimetric, i.e. characterised by a change in colour, or lumophoric, i.e. characterised by a change in luminescence intensity, $\mathrm{I}_{\mathrm{L}}$, or lifetime, $\tau$. In this paper the basic concepts behind the major, and some minor, different luminescent optical sensors for carbon dioxide that have been reported in the literature are discussed and illustrated.

\section{THE TWO TYPES OF CARBON DIOXIDE OPTICAL SENSOR SYSTEMS}

Almost all of the optical sensors for carbon dioxide (colourimetric and lumophoric) can be classified initially into one of two major categories, namely: wet or dry sensors.

\subsection{Wet Optical Sensors for Carbon Dioxide}

The basic characteristics of any wet carbon dioxide optical sensor are: (i) a pH-sensitive dye (anionic form, $\mathrm{D}^{-}$; protonated form, DH), (ii) a luminescent dye (dyes (i) and (ii) are usually one and the same), (iii) an aqueous encapsulation medium, usually containing some sodium bicarbonate, in which the dye(s), (i) and (ii), are dissolved or dispersed and (iv) a gas-permeable, ion-impermeable membrane (GPM) used to cover the wet sensor layer. A schematic illustration of such a typical wet optical sensor for carbon dioxide and its features is given in figure 1. Table 1 lists many of the wet optical sensors for carbon dioxide that have been reported to date and provides details of: (i) the luminescent dyes and encapsulating solutions used, (ii) what kind of analyses they were used for, i.e. gaseous or dissolved carbon dioxide, and (iii) the type of measurement required, i.e. luminescence intensity or lifetime ${ }^{17-35}$. A key to all the abbreviations used in this, and all other tables and in the text, is provided at the end of this article. Structures of some of the key luminescent dyes listed in Table 1 are illustrated in figure 2 . 


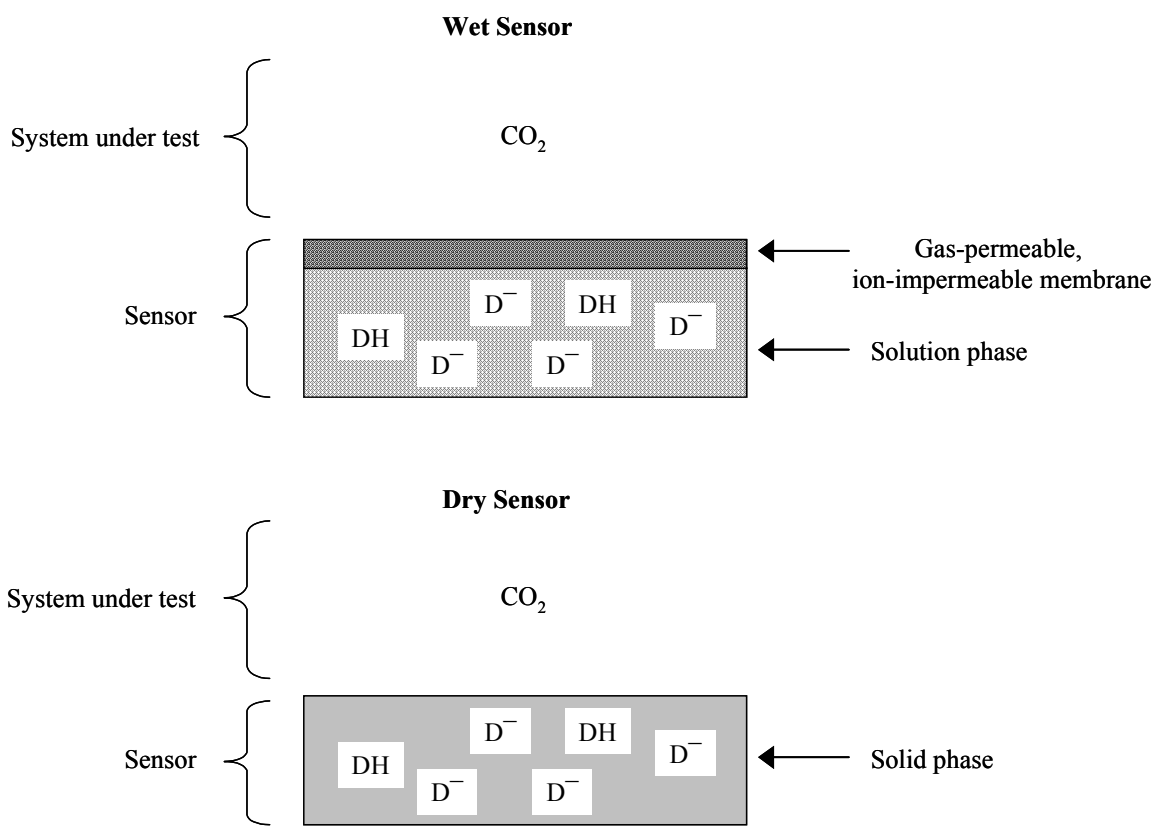

Figure 1. Schematic illustration of the main features of the two different optical sensors for carbon dioxide, namely wet and dry sensors.

The basic principles of operation behind all wet optical sensors for carbon dioxide are very simple and similar to those that underpin the Severinghaus carbon dioxide electrode $^{7}$. Thus, in a typical wet optical sensor for carbon dioxide, the carbon dioxide in the test medium (gaseous or aqueous) diffuses through the GPM, see figure 1, and rapidly (usually within a few seconds to minutes) establishes an equilibrium with the entrapped aqueous layer of the optical sensor. In an aqueous solution in contact with carbon dioxide the following equilibria are set $u^{7,8}$ :

$$
\begin{gathered}
\mathrm{CO}_{2}(\mathrm{~g}) \Leftrightarrow \mathrm{CO}_{2}(\mathrm{aq}) \\
\mathrm{K}_{1}=3.3 \times 10^{-2} \mathrm{~mol} . \mathrm{dm}^{-3} \cdot \mathrm{atm}^{-1} \\
\mathrm{CO}_{2}(\mathrm{aq})+\mathrm{H}_{2} \mathrm{O} \Leftrightarrow \mathrm{H}_{2} \mathrm{CO}_{3} \\
\mathrm{~K}_{2}=2.6 \times 10^{-3} \\
\mathrm{H}_{2} \mathrm{CO}_{3} \Leftrightarrow \mathrm{H}^{+}+\mathrm{HCO}_{3}^{-} \\
\mathrm{K}_{3}=1.72 \times 10^{-4} \mathrm{~mol}^{-} \mathrm{dm}^{-3} \\
\mathrm{HCO}_{3}^{-} \Leftrightarrow \mathrm{H}^{+}+\mathrm{CO}_{3}^{2-} \\
\mathrm{K}_{4}=5.59 \times 10^{-11} \mathrm{~mol}^{2-d^{-3}}
\end{gathered}
$$


If, as is usually the case, the solution also contains sodium hydroxide or sodium bicarbonate at some known concentration $\left[\mathrm{Na}^{+}\right]$, it can be shown that at equilibrium the relationship between the partial pressure of carbon dioxide, $\mathrm{P}_{\mathrm{CO} 2}$, and the proton concentration in the aqueous solution is as follows:

$$
\alpha . \mathrm{P}_{\mathrm{CO} 2}=\left[\mathrm{H}_{2} \mathrm{CO}_{3}\right]=\frac{\left[\mathrm{H}^{+}\right]^{3}+\left[\mathrm{H}^{+}\right]^{2}\left[\mathrm{Na}^{+}\right]-\mathrm{K}_{\mathrm{w}}\left[\mathrm{H}^{+}\right]}{\mathrm{K}_{3}\left(\left[\mathrm{H}^{+}\right]+2 \mathrm{~K}_{4}\right)}
$$

Where $\alpha=\mathrm{K}_{1} \mathrm{~K}_{2}\left[\mathrm{H}_{2} \mathrm{O}\right]$, and $\mathrm{K}_{\mathrm{w}}$ is the water dissociation constant $\left(\mathrm{K}_{\mathrm{w}}=\left[\mathrm{H}^{+}\right]\left[\mathrm{OH}^{-}\right]=10^{-14}\right.$ $\left.\mathrm{mol}^{2} \mathrm{dm}^{-6}\right)$.

The Severinghaus electrode takes advantage of the above set of equilibria, i.e. the acidic nature of carbon dioxide, and monitors the value of the $\mathrm{P}_{\mathrm{CO} 2}$ in the test medium via the $\mathrm{pH}$ change it induces in the entrapped sodium bicarbonate layer using a $\mathrm{pH}$ electrode. In the Severinghaus electrode, and most wet optical sensors for carbon dioxide, the level of sodium bicarbonate in the trapped internal aqueous layer is sufficiently high (typically $10^{-2} \mathrm{~mol} . \mathrm{dm}^{-3}$ ) that eqn. (6) reduces to:

$$
\alpha \cdot \mathrm{P}_{\mathrm{CO} 2}=\left[\mathrm{H}_{2} \mathrm{CO}_{3}\right] \approx\left[\mathrm{H}^{+}\right]\left[\mathrm{Na}^{+}\right] / \mathrm{K}_{3}
$$

i.e. $\mathrm{P}_{\mathrm{CO} 2}$ is proportional to $\left[\mathrm{H}^{+}\right]$.

Most of the wet optical sensors for carbon dioxide listed in Table 1 exploit the same equilibria as the Severinghaus electrode, but use a $\mathrm{pH}$ sensitive dye $\left(\mathrm{DH} / \mathrm{D}^{-}\right)$, rather than a $\mathrm{pH}$ electrode, to determine the acid concentration $\left[\mathrm{H}^{+}\right]$, in the thin aqueous bicarbonate layer. In an aqueous solution containing a luminescent $\mathrm{pH}$-sensitive dye, the key equilibria are summarised by eqn.s (2)-(5) and, the following transduction step:

$$
\begin{gathered}
\mathrm{DH} \Leftrightarrow \mathrm{H}^{+}+\mathrm{D}^{-} \\
\mathrm{K}_{\mathrm{a}}(\mathrm{DH})
\end{gathered}
$$

Where $\mathrm{DH}$ and $\mathrm{D}^{-}$are the protonated and deprotonated form of the dye and $\mathrm{K}_{\mathrm{a}}(\mathrm{DH})$ is the acid dissociation constant for the dye; note: by definition, $\mathrm{pK}_{\mathrm{a}}=-\log \left(\mathrm{K}_{\mathrm{a}}\right)$.

$\mathrm{DH}$ and $\mathrm{D}^{-}$usually have completely different absorption and emission spectral properties. The fluorescent $\mathrm{pH}$-indicating dye, 1-hydroxy-pyrene-3,6,8-trisulfonate (pyranine), or HPTS for short, so often used in optical sensors for carbon dioxide (see Table 1), provides a good illustration of an almost ideal lumophore for use in luminescence, intensity-based sensors for carbon dioxide. The structure of $\mathrm{D}^{-}$for HPTS is illustrated in fig. 2 and the photochemical properties of both $\mathrm{D}^{-}$and DH for HPTS are summarised $^{36,37}$ in table 2 and their features illustrated via the reaction scheme in fig. 3. It can be seen from this data that the protonated and deprotonated forms of HPTS have very different $\lambda_{\max }$ absorption and emission values and that over a wide $\mathrm{pH}$ range any luminescence is due to the electronically excited state of $\mathrm{D}^{-}$, i.e. HPTS, which luminesces at $510 \mathrm{~nm}$, even if DH is excited. HPTS is often used as the pH indicator in carbon dioxide optical sensors because of its: (i) near-ideal $\mathrm{pK}_{\mathrm{a}}$ for monitoring changes in $\mathrm{P}_{\mathrm{CO} 2}$ associated with patient monitoring, (ii) high stability and water solubility, (iii) strong visible absorption band and (iv) large Stokes shift emission band $\left(\lambda_{\max }\left(D^{-}\right)=455 \mathrm{~nm} ; \lambda_{\text {em }}\left(D^{-*}\right)=512 \mathrm{~nm}\right)$. 
Table 1: 'Wet' luminescent indicator systems for carbon dioxide

\begin{tabular}{|c|c|c|c|c|}
\hline $\begin{array}{l}\text { Luminescent } \\
\text { dye }\end{array}$ & Encapsulating medium* & $\begin{array}{l}\text { Gaseous }(\mathrm{g}) \text { or } \\
\text { dissolved }(\mathrm{d}) \mathrm{CO}_{2} \\
\text { measurement }\end{array}$ & $\begin{array}{l}\text { Intensity }(\mathrm{I}) \text { or } \\
\text { lifetime }(\tau) \\
\text { measurement }\end{array}$ & Ref. \\
\hline BMUB & $\begin{array}{l}\text { Aqueous sodium } \\
\text { bicarbonate in agarose }\end{array}$ & $\mathrm{g}$ & I & $17-19$ \\
\hline HPTS & $\begin{array}{l}\text { Aqueous sodium } \\
\text { bicarbonate in agarose }\end{array}$ & $\mathrm{g}$ & I & 20 \\
\hline HPTS & $\begin{array}{l}\text { Dye attached to a strong } \\
\text { anion-exchange } \\
\text { membrane, soaked in } \\
\text { aqueous sodium } \\
\text { bicarbonate }\end{array}$ & $\mathrm{d}$ & I & 21 \\
\hline $\mathrm{AcFl}$ & $\begin{array}{l}\text { A polyHEMA hydrogel, } \\
\text { saturated with an aqueous } \\
\text { solution of sodium } \\
\text { chloride and sodium } \\
\text { bicarbonate }\end{array}$ & $\mathrm{d}$ & I & 22 \\
\hline HPTS & $\begin{array}{l}\text { Dye covalently } \\
\text { immobilized in cellulose } \\
\text { granules embedded in a } \\
\text { hydrogel soaked in } \\
\text { aqueous sodium } \\
\text { bicarbonate }\end{array}$ & $\mathrm{g}$ & $\mathrm{I}$ & 23 \\
\hline $\begin{array}{l}\text { Fl and other } \\
\text { Fl } \\
\text { derivatives }\end{array}$ & $\begin{array}{l}\text { (a) dye adsorbed onto } \\
\text { porous glass bead with } \\
\text { hygroscopic lithium } \\
\text { nitrate to keep moist and } \\
\text { (b) an aqueous solution. } \\
\text { In both cases, the sensor } \\
\text { element was sealed in a } \\
\text { capillary tube, with a gas } \\
\text { bubble as the GPM. } \\
\text { Photobleaching reduced } \\
\text { using an antioxidant } \\
\text { additive.. }\end{array}$ & $\mathrm{g}$ & $\mathrm{I}$ & 24 \\
\hline $\begin{array}{l}\text { Fl and } \\
\text { HPTS }\end{array}$ & $\begin{array}{l}\text { Fl copolymersised with } \\
\text { HEMA or HPTS- } \\
\text { adsorbed-onto } \\
\text { acrylamide. Both sensors } \\
\text { soaked in aqueous sodium } \\
\text { bicarbonate }\end{array}$ & $\mathrm{g}$ & $\mathrm{I}$ & 25 \\
\hline
\end{tabular}


Table 1: (Continued)

\begin{tabular}{|c|c|c|c|c|}
\hline $\begin{array}{l}\text { Luminescent } \\
\text { dye }\end{array}$ & Encapsulating medium* & $\begin{array}{l}\text { Gaseous }(\mathrm{g}) \text { or } \\
\text { dissolved }(\mathrm{d}) \mathrm{CO}_{2} \\
\text { measurement }\end{array}$ & $\begin{array}{l}\text { Intensity }(\mathrm{I}) \text { or } \\
\text { lifetime }(\tau) \\
\text { measurement }\end{array}$ & Ref. \\
\hline HPTS & $\begin{array}{l}\text { Aqueous sodium } \\
\text { bicarbonate entrapped in } \\
\text { expanded PTFE (Gore } \\
\text { Tex }^{\mathrm{TM}} \text { ) }\end{array}$ & $\mathrm{d}$ & I & 26 \\
\hline HPTS & $\begin{array}{l}\text { Dye with or without } \\
\text { cross-linked } \\
\text { polyacrylamide beads, } \\
\text { soaked in sodium } \\
\text { bicarbonate and } \\
\text { embedded in silicone } \\
\text { rubber }\end{array}$ & $\mathrm{g}$ & $\mathrm{I}$ & 27 \\
\hline HPTS & $\begin{array}{l}\text { Dye plus cross-linked } \\
\text { with aminoethylcellulose } \\
\text { fibres, embedded in an } \\
\text { ion-permeable } \\
\text { polyurethane based } \\
\text { hydrogel, attached to a } \\
\text { polyester foil. }\end{array}$ & $\mathrm{d}$ & I & 28 \\
\hline c-SNARF & $\begin{array}{l}\text { Dye in aqueous sodium } \\
\text { bicarbonate micelles, } \\
\text { stabilized with PVP, } \\
\text { dispersed in siloxane } \\
\text { polymer. No additional } \\
\text { GPM. }\end{array}$ & g & I & 29 \\
\hline c-SNAFLc & $\begin{array}{l}\text { Dye in aqueous sodium } \\
\text { bicarbonate soaked in an } \\
\text { NVP hydrogel }\end{array}$ & $\mathrm{d}$ & I & 30 \\
\hline $\mathrm{HCA}$ & $\begin{array}{l}\text { MCP added to compress } \\
\text { pH response range in an } \\
\text { aqueous sodium } \\
\text { bicarbonate solution with } \\
\text { sodium chloride added to } \\
\text { match the osmotic } \\
\text { pressure of the salt water. }\end{array}$ & $\mathrm{d}$ & $\mathrm{I}$ & 31 \\
\hline
\end{tabular}

* unless stated otherwise all sensors covered by a GPM (silicone rubber or PTFE usually) 
Table 1: (Continued)

\begin{tabular}{|l|l|c|c|c|}
\hline \multicolumn{1}{|c|}{$\begin{array}{c}\text { Luminescent } \\
\text { dye }\end{array}$} & Encapsulating medium* & $\begin{array}{c}\text { Gaseous (g) or } \\
\text { dissolved (d) } \mathrm{CO}_{2} \\
\text { measurement }\end{array}$ & $\begin{array}{c}\text { Intensity (I) or } \\
\text { lifetime }(\tau) \\
\text { measurement }\end{array}$ & Ref. \\
\hline HPTS & $\begin{array}{l}\text { Non-fluorescent NR } \\
\text { added to compress pH } \\
\text { response range in an } \\
\text { aqueous sodium } \\
\text { bicarbonate solution with } \\
\text { sodium chloride added to } \\
\text { match the osmotic } \\
\text { pressure of the salt water. } \\
\text { NR precipitates at high } \\
\text { ionic strength, so limiting } \\
\text { it use. }\end{array}$ & $\mathrm{d}$ & $\mathrm{I}$ & 31 \\
\hline $\begin{array}{l}\text { Eosin, R6G or } \\
\text { THR }\end{array}$ & $\begin{array}{l}\text { Dyes encapsulated in a } \\
\text { poly(HEMA) hydrogel, } \\
\text { soaked with sodium } \\
\text { bicarbonate and with } \\
\text { FRET acceptor dye PR or } \\
\text { BTB }\end{array}$ & $\mathrm{g}$ & $\tau$ & 32 \\
\hline Ru(pzth ${ }_{2}{ }^{2+}$ & $\begin{array}{l}\text { Dye attached to sephadex } \\
\text { beads that are then made } \\
\text { to gel. }\end{array}$ & $\mathrm{g}$ & $\tau$ & $33-35$ \\
\hline
\end{tabular}

* unless stated otherwise all sensors covered by a GPM (silicone rubber or PTFE usually)

Table 2: Photochemical and Chemical Characteristics of HPTS in aqueous solution ${ }^{36,37}$ and in a plastic film*

\begin{tabular}{|c|c|c|}
\hline Property & HD & $\mathrm{D}^{-}$ \\
\hline Aqueous solution & 455 \\
\hline Absorption $\lambda_{\max } / \mathrm{nm}$ & 403 & 512 \\
\hline Emission $\lambda_{\max } / \mathrm{nm}$ & 435 & 4.8 \\
\hline Excited state lifetime/ns & 5.3 & \multicolumn{2}{|c|}{1.4} \\
\hline $\mathrm{pK}_{\mathrm{a}}$ of HPTS & \multicolumn{2}{|c|}{} \\
\hline $\mathrm{pK}_{\mathrm{a}}$ of excited HPTS & 394 & 467 \\
\hline Plastic film* & 517 \\
\hline Absorption $\lambda_{\max } / \mathrm{nm}$ & 440 & \\
\hline Emission $\lambda_{\max } / \mathrm{nm}$ &
\end{tabular}

*Plastic film comprises ${ }^{37}$ : TAOH as the phase transfer agent, EC as the polymer and TBP as the plasticiser 
<smiles>NS(=O)(=O)c1cc([O-])c2ccc3c(S(=O)(=O)O)cc([O-])c4ccc1c2c43</smiles><smiles>CC(=O)c1ccc(-c2c3ccc(=O)cc-3oc3c2ccc2cc([O-])ccc23)cc1</smiles>

BMUBCSNAFL-<smiles>NCCCCN</smiles><smiles>c1cnc(C2=NCCS2)cn1</smiles>

2-(2-pyrazinyl) thiazole

Figure 2. Structures of selected lumophores listed in table 1 and used in wet optical sensors for carbon dioxide. 
From the data given in table 2 and the schematic illustration of the major processes associated with $\mathrm{HD}$ and $\mathrm{D}^{-}$, in fig. 3 , it would appear that by simply monitoring the emission intensity at $512 \mathrm{~nm}$, due to $\mathrm{D}^{-*}$, of an internal aqueous HPTS solution containing sodium bicarbonate, covered by a GPM, generated using $\lambda_{\text {excit }}=455 \mathrm{~nm}$, it should be possible to determine the proton concentration of the internal aqueous solution and, via eqns. (7) and (8), the level of $\mathrm{P}_{\mathrm{CO} 2}$ in the external medium under test. If HPTS is used under such conditions, provided the concentration of dye used is very small compared to that of the buffer, sodium bicarbonate, then eqns. (7) and (8) can be combined to yield the following expression:

$$
\alpha \cdot \mathrm{P}_{\mathrm{CO} 2}=\left[\mathrm{H}_{2} \mathrm{CO}_{3}\right] \approx \mathrm{K}_{\mathrm{a}}[\mathrm{DH}]\left[\mathrm{Na}^{+}\right] /\left(\mathrm{K}_{3} \cdot\left[\mathrm{D}^{-}\right]\right)
$$

Provided the $\mathrm{pH}$ sensing dye is optically dilute, i.e. absorbance at $\lambda_{\text {excit }}$ is typically $<0.1$, then $\mathrm{I}_{\mathrm{L}}$, the sensor film luminescence due to $\mathrm{D}^{* *}$, in the presence of carbon dioxide at a level of $\mathrm{P}_{\mathrm{CO} 2}$, will be proportional to [D"]. Thus, eqn. (9) becomes:

$$
\alpha \cdot \mathrm{P}_{\mathrm{CO} 2}=\left[\mathrm{H}_{2} \mathrm{CO}_{3}\right] \approx \mathrm{K}_{\mathrm{a}}\left(\mathrm{I}_{\mathrm{L}}{ }^{\mathrm{o}}-\mathrm{I}_{\mathrm{L}}\right)\left[\mathrm{Na}^{+}\right] /\left(\mathrm{K}_{3} \cdot \mathrm{I}_{\mathrm{L}}\right)
$$

where $\mathrm{I}_{\mathrm{L}}{ }^{\circ}$ is the measured luminescence intensity for the system in the absence of carbon dioxide, i.e. when all the dye, HPTS in this case, is in its deprotonated form, D- Note that as a consequence of eqn. (10), the smaller the concentration of sodium bicarbonate, the narrower and lower the dynamic range of the carbon dioxide optical sensor.

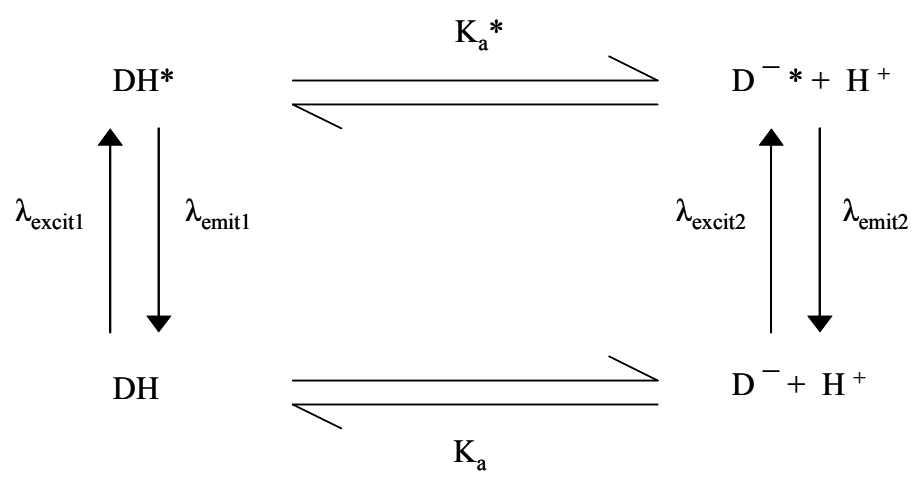

Figure 3. Schematic illustration of the major processes ${ }^{36,37}$ associated with the electronic excitation of either the protonated, $\mathrm{DH}$, or deprotonated, $\mathrm{D}^{-}$, forms of a luminescent, $\mathrm{pH}$-sensitive dye, such as HPTS. Usually, the $\mathrm{pK}_{\mathrm{a}}$ of the electronically excited state of $\mathrm{DH}$ is much lower than that of its ground state, i.e. $\mathrm{pK}_{\mathrm{a}}{ }^{*}<<\mathrm{pK}_{\mathrm{a}}$. As a consequence over a wide range of $\mathrm{pH}$ the only luminescence that will be observed is due to $\mathrm{D}^{*}$ even if $\mathrm{DH}$ is excited. This is certainly the case for D = HPTS.

Other factors that will affect the above equilibria, both with respect to the equilibria associated with carbon dioxide and the deprotonation of the dye include: temperature and ionic strength. With either temperature or ionic strength, an increase invariably produces a decrease in the sensitivity of the carbon dioxide wet, luminescent optical sensor, or, as others $^{26}$ have more positively put it, 'an increase in the dynamic range'. Either way, 
optical sensors for carbon dioxide are notoriously sensitive to changes in temperature, ionic strength (relevant to dissolved carbon dioxide measurements) and humidity (relevant to gaseous carbon dioxide measurements), and this fact should never be forgotten.

One of the first luminescence intensity-based wet optical sensors for carbon dioxide, featured in table 1, was reported by Lübbers and Opitz ${ }^{17-19}$ in 1975 , using the $\mathrm{pH}$ sensitive dye, $\beta$-methyl umbelliferon, BMUB, $\left(\lambda_{\text {excit }}\left(D^{-}\right) 357 \mathrm{~nm} ; \lambda_{\text {em. }}\left(D^{-*}\right) 445 \mathrm{~nm}\right)$, dissolved in a thin aqueous layer containing: $5 \mathrm{mmol} \mathrm{dm}$ sodium bicarbonate with $1 \%$ agarose added for improved mechanical stability and covered by a gas-permeable, ion-impemeable membrane, such as PTFE. Eight years later these same authors reported the first 'wet' optical HPTS sensor for carbon dioxide, using otherwise the same formulation as their PTFE/BMUB/agarose/sodium bicarbonate sensor ${ }^{20}$. Figure 4(a) illustrates a typical set of excitation spectra $\left(\lambda_{\text {em. }}=510 \mathrm{~nm}\right)$ reported by these workers for their PTFE/HPTS/agarose/sodium bicarbonate sensor as a function of $\mathrm{P}_{\mathrm{CO} 2}$. Figure 4(b) illustrates the observed variations in $\mathrm{I}_{\mathrm{L}}$ as a function of $\mathrm{P}_{\mathrm{CO} 2}$ for the Lübbers and Opitz HPTS carbon dioxide sensor for 3 different concentrations of sodium bicarbonate in the thin aqueous layer. From eqn. (10) a plot of the sensor's luminescence intensity at $510 \mathrm{~nm}, \mathrm{I}_{\mathrm{L}}$, in the following form: $\left(\mathrm{I}_{\mathrm{L}}{ }^{0}-\mathrm{I}_{\mathrm{L}}\right) / \mathrm{I}_{\mathrm{L}}$ as a function of $\mathrm{P}_{\mathrm{CO} 2}$ should generate a straight line with a zero intercept. This prediction is confirmed for the Lübbers and Optiz HPTS carbon dioxide sensor by the plot of the results in fig. 4(b) in this latter format, illustrated in the insert diagram of fig. 4(b) for a range (1-6 mM) of different concentrations of sodium bicarbonate in the thin aqueous layer. Note the decrease in sensitivity of the optical sensor with increasing sodium bicarbonate concentration, as predicted by eqn. (10) and highlighted earlier.

Most optical sensors for carbon dioxide give a response curve, i.e. $\mathrm{I}_{\mathrm{L}} \mathrm{vs.} \mathrm{P}_{\mathrm{CO} 2}$ curve, similar in nature to those illustrated by the main diagram in fig. 4(b). Given the nature of eqn (10), it is not surprising to note that such sensors are said ${ }^{19,38}$ to exhibit a hyperbolic response, or to be hyperbolic-type sensors. One of the common features of a hyperbolic response sensor is a shorter response time (say for $90 \%$ of the overall signal change) than the corresponding recovery time, with the difference increasing with increasing magnitude in the change in $\mathrm{P}_{\mathrm{CO} 2}$. This feature is readily explained if the response and recovery process are both controlled by the same process, such as the diffusion of carbon dioxide into and out of the sensor ${ }^{38}$.

The pioneering work of Lübbers and Opitz ${ }^{17-20}$ in the area of optical sensors for carbon dioxide helped encourage the subsequent generation of many other luminescence intensity-based optical sensors for carbon dioxide, as indicated by the extensive list in table 1. Subsequent variations on the Lübbers and Opitz wet luminescence intensity-based carbon dioxide optical sensor include using the dye encapsulated in, or bound to, a sponge like material, soaked in an aqueous sodium bicarbonate solution ${ }^{26}$, or the dye attached to an inert support in a 'sea' or gel of bicarbonate solution ${ }^{23,27,28}$. In all cases listed in table 1 the sensors were protected by a gas-permeable, ion-impermeable layer, mainly to prevent water loss through evaporation to the usual gaseous medium under test. When such sensors were used to monitor dissolved levels of carbon dioxide, the gas-permeable membrane prevents the dissolution of the thin aqueous layer, containing the luminescent, $\mathrm{pH}$-sensitive dye and sodium bicarbonate. 


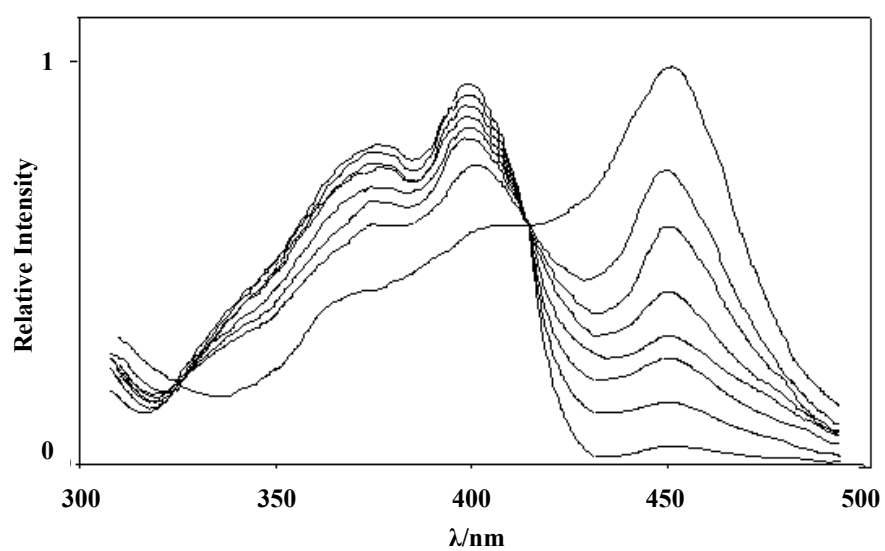

(a)

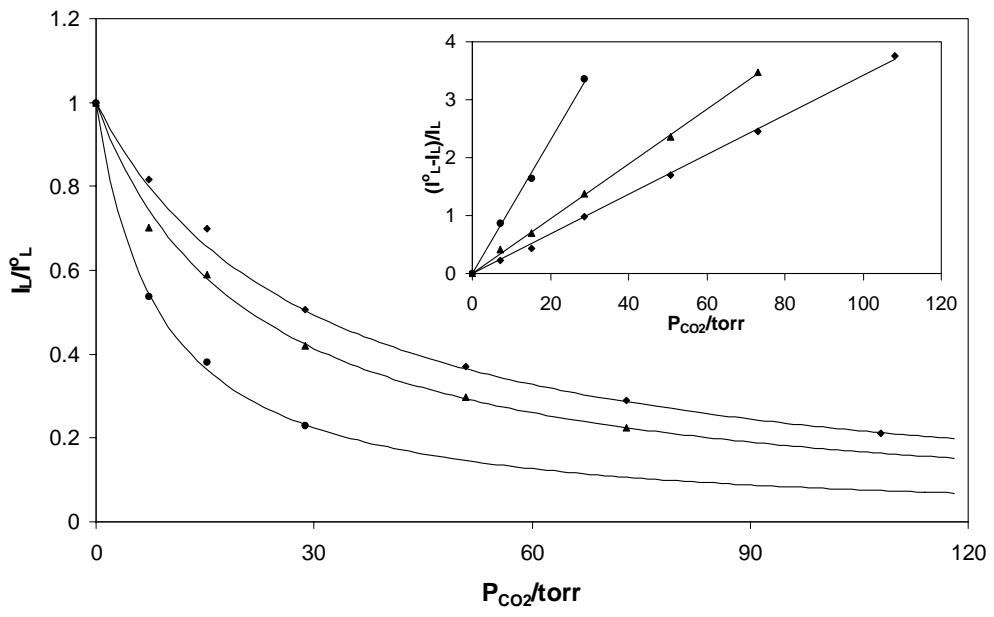

(b)

Figure 4. (a) Typical corrected excitation spectra $\left(\lambda_{\mathrm{em}}=510 \mathrm{~nm}\right)$ for a wet optical sensor for carbon dioxide comprising: PTFE/HPTS/agarose/sodium bicarbonate solution, when exposed to the following levels of $\% \mathrm{CO}_{2}$ in the gas phase under test (from top to bottom): $0,1,2,4,7,10,20$ and 100, respectively ${ }^{20}$. (b) Plot of the relative intensity of emission $\left(\mathrm{I}_{\mathrm{L}} / \mathrm{I}_{\mathrm{L}}{ }^{0}\right)$ exhibited by a PTFE/HPTS/agarose/sodium bicarbonate solution optical sensor $\left(\lambda_{\text {excit. }}=\right.$ blue LED $\left.\left(\lambda_{\max }=490 \mathrm{~nm}\right) ; \lambda_{\text {em. }}=510 \mathrm{~nm}\right)$ as a function of $\mathrm{P}_{\mathrm{CO} 2}$, with the concentration of the sodium bicarbonate used set at: $6(\bullet), 3(\boldsymbol{\Delta})$ and $1(\bullet) \mathrm{mM}$, respectively. The insert diagram illustrates the good linear relationship between $\left(\mathrm{I}_{\mathrm{L}}{ }^{0}-\mathrm{I}_{\mathrm{L}}\right) / \mathrm{I}_{\mathrm{L}}$ and $\mathrm{P}_{\mathrm{CO} 2}$, for the three different films as predicted by eqn. $(10)^{20}$.

As noted above, most of the wet luminescence indicator systems reported to date and listed in table 1 are based on the measurement of the intensity of luminescence of a 
$\mathrm{pH}$-sensitive dye, such as HPTS as a function of $\mathrm{P}_{\mathrm{CO} 2}$. However, in at least one case listed in table 1 , luminescence lifetime, $\tau$, measurements are used instead to ascertain the $\mathrm{pH}$ of the internal aqueous sodium bicarbonate solution and so, via eqn. (10), the partial pressure of carbon dioxide in the external test medium ${ }^{32}$. This example uses a very different method of transduction, pioneered by Lakowicz and his co-workers, which involves the use of long-range, non-radiative Fluorescence Resonance Energy Transfer $(\text { FRET })^{32}$. In this and all FRET sensing systems for carbon dioxide reported here the colour change exhibited by a $\mathrm{pH}$-insensitive colourimetric dye (the acceptor, $\mathrm{A}^{-}$) is used to affect the decay time of a, usually, $\mathrm{pH}$-sensitive lumophore (the donor, $\mathrm{D}$ ). In such sensor systems, the electronically excited state of the donor lumophore, i.e. D*, is usually quenched by the deprotonated form of the acceptor $\mathrm{pH}$-sensitive dye, $\mathrm{A}^{-}$i.e.

$$
\mathrm{D}^{*}+\mathrm{A}^{-} \stackrel{\text { FRET }}{\longrightarrow} \mathrm{D}+\mathrm{A}^{-*}
$$

Where $\mathrm{A}^{* *}$ is the electronically excited state of the deprotonated acceptor, $\mathrm{A}^{* *}$. Typically $\mathrm{A}^{-*}$ undergoes rapid non-radiative decay to return to the ground-state of the dye, $\mathrm{A}^{-}$, i.e. $\mathrm{A}^{-*}$ does not usually luminesce and, if it does, not at the same wavelengths as $\mathrm{D}^{*}$. The protonated form of the quencher, $\mathrm{AH}$, is assumed either not to quench $\mathrm{D}^{*}$ or, if it does, at a rate that is significantly lower than that for $\mathrm{A}^{-}$.

In a FRET-based carbon dioxide sensor, in the absence of carbon dioxide the $\mathrm{pH}$ of the encapsulation medium, in this case aqueous sodium bicarbonate, is initially set sufficiently high that all, or most of the $\mathrm{pH}$-sensitive, colourimetric acceptor dye is present in its anionic form, $\mathrm{A}^{-}$, and thus should, ideally, quench the $\mathrm{pH}$-insensitive, electronically-excited luminescent donor dye molecules, D*, very effectively and efficiently via reaction (11). As a consequence, the lifetime of the luminescent donor will be very short and at a minimum value, $\tau_{0}$, in the absence of any carbon dioxide in the medium under test. However, if carbon dioxide is present, then the $\mathrm{pH}$ of the sensor's encapsulation medium will be decreased and the concentration of the acceptor quencher, in reaction (11), $\mathrm{A}^{-}$will decrease, due to the following equilibrium:

$$
\begin{gathered}
\mathrm{A}^{-}+\mathrm{H}^{+} \Leftrightarrow \mathrm{AH} \\
1 / \mathrm{K}_{\mathrm{a}}(\mathrm{AH})
\end{gathered}
$$

where $\mathrm{K}_{\mathrm{a}}(\mathrm{AH})$ is the acid dissociation constant for the protonated form of the acceptor, $\mathrm{AH}$. As a consequence, $\mathrm{D}^{*}$ will be less quenched via reaction (11) the higher the level of carbon dioxide in the test medium. Consequently, the measure lifetime of $\mathrm{D}^{*}, \tau$, will increase with increasing $\mathrm{P}_{\mathrm{CO} 2}$, i.e. $\tau>\tau_{0}$. As noted above, this transduction process presumes that $\mathrm{AH}$ doesn't itself quench $\mathrm{D}^{*}$, and this assumption appears fairly reasonable given the stringent conditions required to observe efficient quenching of an electronically excited donor by FRET in the first place.

Thus, in order for FRET to be most effective the following conditions need to be satisfied: (i) the absorption spectrum of the colourimetric acceptor should overlap strongly with the emission spectrum of the lumophoric donor, (ii) both transitions, $\mathrm{D}^{*} \rightarrow \mathrm{D}$ and $\mathrm{A}^{-} \rightarrow \mathrm{A}^{-*}$, should be highly allowed and, finally, (iii) (for unlinked D-A pairs) $\mathrm{A}^{-}$should be $c a \cdot 1-10 \mathrm{mmol}^{-3} \mathrm{dm}^{-3}$ (so that $\mathrm{D}$ and $\mathrm{A}^{-}$are within the Förster

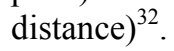


In the pioneering work of Lakowicz and his co-workers on FRET optical sensors for carbon dioxide, the donors used were: Texas Red Hydrazine (TRH), Eosin and Rhodamine 6G (R6G) and the acceptors used were: Bromothymol Blue (BTB) and Phenol Red $(\mathrm{PR})^{32}$. In this work and most, if not all, lifetime-based optical carbon dioxide sensor studies, the lifetime of the luminescent donor at different levels of $\mathrm{P}_{\mathrm{CO} 2}$ were determined by a phase-modulation technique ${ }^{39}$. In this method the increase in lifetime of the donor is detected in the frequency, rather than the time, domain, as a change in the phase angle, between the modulated excitation light and the forced oscillation of the emission from the electronically excited donor molecules. The experimental observables are the shift in phase angle of the emission, $\phi$, and its modulation, $m$, in intensity, both relative to the phase and modulation of the source. An average decay time, $\tau$, can be calculated from the phase angle shift or modulation through either one of the following equations ${ }^{39}$ :

$$
\tan \phi=\omega \tau
$$

and

$$
m=\left(1+\omega^{2} \tau^{2}\right)^{-1 / 2}
$$

where $\omega$ is the angular modulation frequency $(=2 \pi f$, where $f=$ frequency in $\mathrm{Hz}$ of the modulated excitation light). A simple illustration of the output of a phase-modulated system is illustrated in figure 5 . The broken line depicts the sinusoidal variation in excitation light, in this case set at a typical value $f=100 \mathrm{MHz}$, as a function of time. The solid line shows how the emitted light intensity generated by a fluorophore, with a lifetime, $\tau$, (in this case $\tau$ is set at $10 \mathrm{~ns}$ ), comparable to $1 / f$ would vary as a function of time if it absorbed some of the excitation light. Due to the finite lifetime of the excited state, the emission will be delayed in time relative to the excitation, which is measured as a phase shift, $\phi$, which can be used to calculate $\tau$ via eqn. (13). The relative amplitude of the emission is also reduced compared to that of the excitation. This process of demodulation allows the parameter, $m$, to be calculated via the following equation:

$$
m=(\mathrm{A} / \mathrm{B}) /(\mathrm{a} / \mathrm{b})
$$

using the data in figure 5. For any value of $m$ a value of $\tau$ can be calculated via eqn. (14). It should be briefly noted that the above equations hold only if the luminescence decay is described by a single-exponential decay. Interestingly, for FRET-based carbon dioxide sensors, and, for that matter, most FRET-based sensors, e.g. for oxygen, invariably the assumption of mono-exponential excited state decay kinetics is not valid, especially for luminescent dyes dispersed in a heterogeneous medium such as a polymer ${ }^{40,41}$. Fortunately, as we shall see, the variation in the apparent average lifetime, as measured using phase modulation spectroscopy and eqn. (13), as a function of $\mathrm{P}_{\mathrm{CO} 2}$ still appears to fit the simple equations, based on the assumption of a single exponential decay, that allow the data to be linearised. 


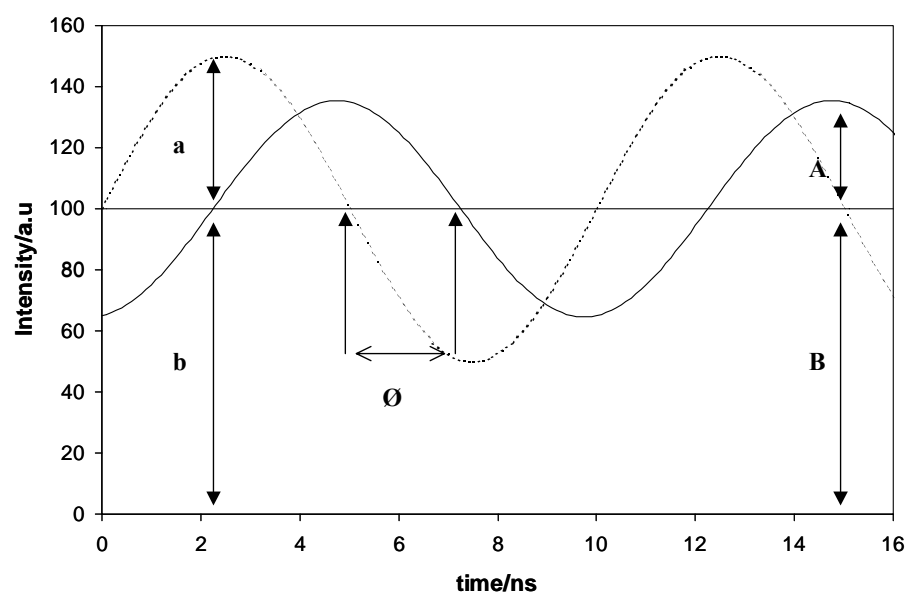

Figure 5. Schematic illustration of the variation in intensity of a modulated excitation light source (broken line) operating at a frequency $=100 \mathrm{MHz}$ and the resulting phase-shifted luminescence (solid line) generated by a lumophore, which absorbs some of the excitation light, with a lifetime of $10 \mathrm{~ns}$. Under such conditions, from eqn. (13), $\phi=86.96^{\circ}$ (三2.25 ns). "A" and "B" and "a" and "b" in this diagram are the measured "amplitude" and "background" light intensity levels for the lumophore and excitation source, respectively, from which a value for $m$ can be calculated using eqn. (15).

Typically, for any FRET-based sensor system, an optimum single modulation frequency is chosen, typically $f \cong 1 / \tau$, and the values of $\phi$ exhibited by the FRET-based sensor are then measured as a function of $\mathrm{P}_{\mathrm{CO} 2}$. Thus, Lakowicz and his co-workers used $f=133$ or $155 \mathrm{MHz}$ in their early studies of FRET-based wet optical sensors for carbon dioxide $^{32}$ using the donor-acceptor pairs: TRH-BTB, Eosin-PR and R6G-PR in a poly(HEMA) hydrogel noted earlier. The observed variations of the relative phase angle shifts as a function of $\mathrm{P}_{\mathrm{CO} 2}$ for these three different sensors are illustrated in fig. 6 and show that the TRH-BTB and Eosin-PR sensors are particularly responsive to variations in the level of carbon dioxide using FRET $^{32}$.

The use of lifetime measurements, via time-resolved or phase-modulated techniques, has the advantages that the measured decay times are generally not dependent upon the macroscopic optical properties of the sample and are not sensitive to the fluctuations in the exciting light intensity. In contrast, the more traditional steady-state intensity measurements, which are used for the intensity-based optical sensors for carbon dioxide that dominate table 1 , are sensitive to these parameters and thus measurements will be sensitive to light loss, lamp drift and dye bleaching, amongst other things. These drawbacks, which necessitate regular sensor calibration in intensity-based luminescence systems, are mitigated only by the simplicity of the measurements and the inexpensive nature of the associated necessary equipment. 


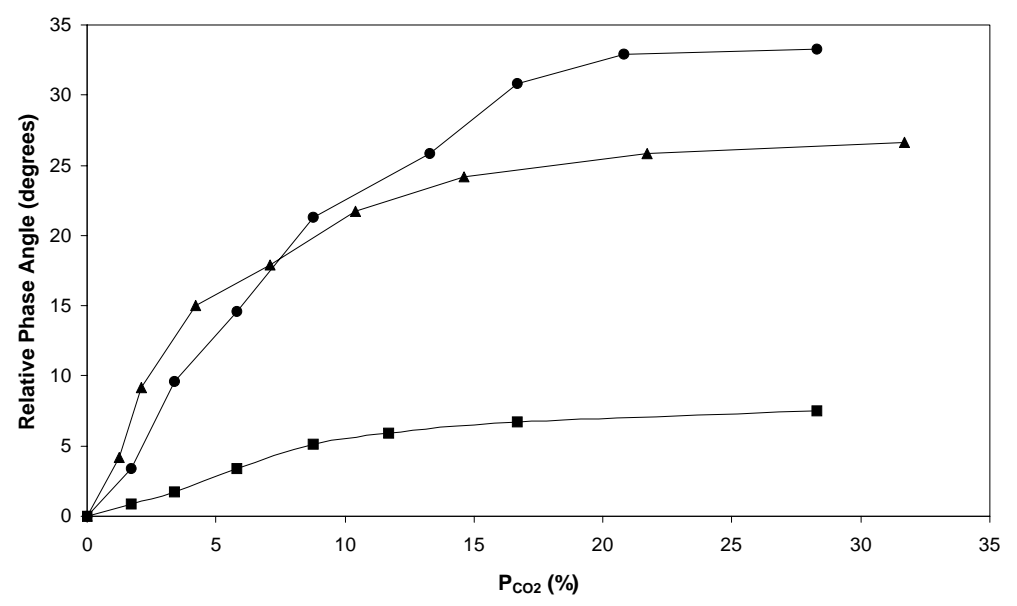

Figure 6. Dependence of the donor relative phase angle on $\mathrm{P}_{\mathrm{CO} 2}$ for a series of different donor-acceptor pairs in a poly(HEMA)-hydrogel at $25^{\circ} \mathrm{C}$. The donor-acceptor pairs used were: THR-BTB $\left(\lambda_{\text {em. }}=600 \mathrm{~nm} ; f=133\right.$ $\mathrm{MHz})(\bullet)$, Eosin-PR $\left(\lambda_{\mathrm{em}}=580 \mathrm{~nm} ; f=155 \mathrm{MHz}\right)(\boldsymbol{\Delta})$; and R6G-PR $\left(\lambda_{\mathrm{em} .}=600 \mathrm{~nm} ; f=133 \mathrm{MHz}\right)(\boldsymbol{\bullet})$. In all cases $\lambda_{\text {excit. }}=543 \mathrm{~nm}^{32}$.

Some of the difficulties associated with luminescence intensity measurements can also be obviated using a simple wavelength-ratiometric method. For example, Uttamlal and Walt developed a fibre-optic carbon dioxide sensor for fermentation monitoring ${ }^{26}$, in which the lumophore, HPTS, was dissolved in a sodium bicarbonate solution and entrapped in an expanded PTFE support held at the distal end of the optical fibre by a gas permeable membrane. In this work, the luminescence emission of the optical sensor at $515 \mathrm{~nm}$ (due to $\mathrm{D}^{*}$ ) was measured for two different excitation wavelengths, namely: $470 \mathrm{~nm}$ (which excites $\mathrm{D}^{-}$only) and 405 (which excites mostly $\mathrm{DH}$ ). The ratios of the two measured luminescence intensities, i.e. $\mathrm{I}_{\mathrm{L}}(470) / \mathrm{I}_{\mathrm{L}}(405)$, were used ${ }^{26}$ to calibrate the sensor, both in $0.45 \mathrm{M}$ sodium chloride solution and distilled water, as illustrated by the data in fig. 7. By ratioing the luminescence intensities measured at the two different excitation wavelengths, it is possible to eliminate problems due to errors arising from lamp intensity fluctuations and drifts in the photodetection system. If the lumophore is present at optically dilute concentrations, (i.e. its absorbance at $\lambda_{\text {excit }}$ is $<0.1$ then this ratiometric method can also compensate for changes in dye concentration. This wavelength - ratiometric compensation method ${ }^{26}$ obviously assumes that any change in optical artefact affects both wavelengths in a similar manner and this and other underlying assumptions need to be recognised. However, the above wavelengthratiometric technique has proved to be a popular method for reducing errors and providing reliable calibration plots for intensity-based carbon dioxide, and $\mathrm{pH}$, optical sensors.

In contrast to intensity-base measurements, lifetime measurements, whether they be time resolved or phase modulated, often require expensive, bulky and sophisticated equipment. Thus, in their early work on FRET-based optical sensors for carbon dioxide, Lakowicz and his co-workers used several expensive lasers, (such as a $543 \mathrm{~nm}-\mathrm{He}-\mathrm{Ne}$ laser and a cavity dumped dye laser $)^{32,39}$, which had their intensities modulated with an 
acoustic-optic modulator, working at, typically, $155 \mathrm{MHz}$. Subsequent to this work, these and other workers have attempted to address the issue of the prohibitive expense of lifetime measurements for optical sensor interrogation by studying longer-lived luminescent donor dyes in FRET-based systems that can be probed using cheap diode light sources, modulated at considerably lower frequencies, i.e. $f<100 \mathrm{MHz}$, than those used previously. This move to more affordable lifetime measurement systems for carbon dioxide optical sensors will become more apparent in the next section.

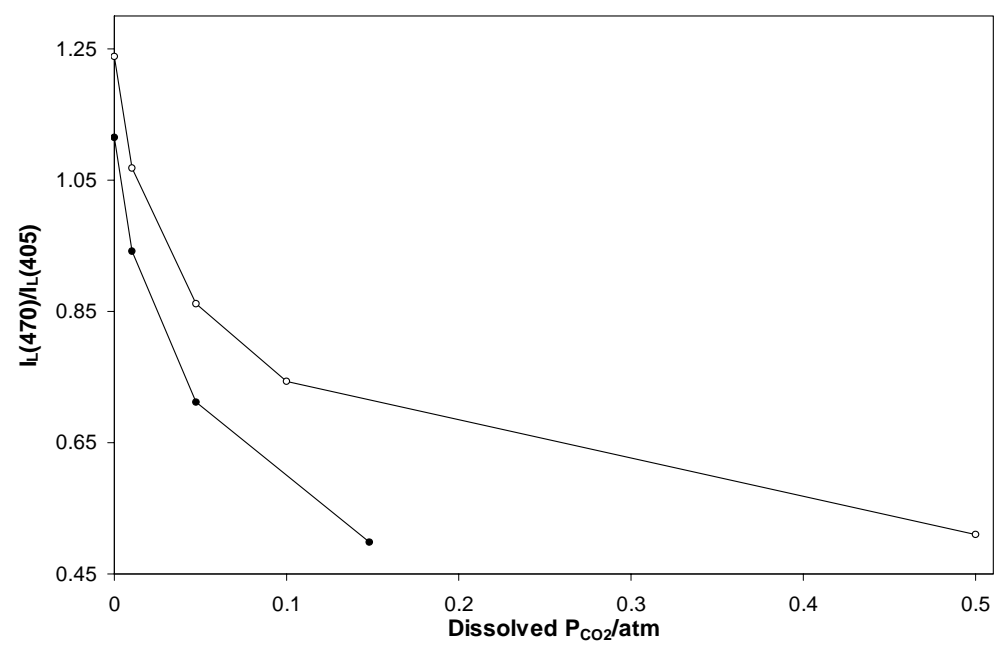

Figure 7. Observed ${ }^{26}$ variation is the ratio of the intensity of luminescence due to HPTS when excited at 470 and $405 \mathrm{~nm}$, i.e. $\mathrm{I}_{\mathrm{L}}(470) / \mathrm{I}_{\mathrm{L}}(405)$ as a function of the level of dissolved carbon dioxide, $\mathrm{P}_{\mathrm{CO} 2}$. In this work the sensor used comprised: PTFE/HPTS/sodium bicarbonate solution, with the latter two entrapped in an expanded PTFE support. The measurements were performed using $0.45 \mathrm{M}$ sodium chloride $(0)$ and distilled water $(\bullet)$.

In the area of optical sensors for carbon dioxide, the use of FRET has the added advantage over intensity measurements that the lumophore itself no longer needs to be $\mathrm{pH}$-sensitive, which is very liberating since the number of dyes that are both $\mathrm{pH}$-sensitive and luminescent are very limited. Thus, a FRET-carbon dioxide sensor can use a wide range of $\mathrm{pH}$-insensitive donor lumophores, provided a suitable colourimetric, $\mathrm{pH}-$ sensitive acceptor dye can be found. Fortunately, there are many such donor-acceptor dye combinations and, as a consequence, there is the potential for a wider variety of FRET-based carbon dioxide sensors than there are of luminescence-based ones.

Finally, under the heading of wet optical sensors for carbon dioxide, it is appropriate to mention the work of Orellana and his co-workers ${ }^{33-35}$ and their development of a carbon dioxide sensor based on the quenching of a novel ruthenium (II) complex by proton transfer. In this work, the novel lumophore employed was the tris(2-(2pyrazinyl)thiazole)-ruthenium (II) cation, $\mathrm{Ru}(\mathrm{pzth})_{3}{ }^{2+}$, the structure of which is illustrated in fig. 2. This complex is water soluble and absorbs strongly at $331 \mathrm{~nm}\left(\varepsilon_{\max }=47000\right.$ $\left.\mathrm{dm}^{3} \mathrm{~mol}^{-1} \mathrm{~cm}^{-1}\right)$ and $460 \mathrm{~nm}\left(\varepsilon_{\max }=17000 \mathrm{dm}^{3} \mathrm{~mol}^{-1} \mathrm{~cm}^{-1}\right)$ and emits at $652 \mathrm{~nm}$. The 
proton transfer agent used to quench the ruthenium (II) complex is a Brönsted acid (HB), and was typically dihydrogen phosphate or dihydrogenphthalate. Fig. 8 illustrates the essential features of the various processes involved in the quenching of $\mathrm{Ru}(\mathrm{pzth})_{3}{ }^{2+}$ (equivalent to $\mathrm{D}^{-}$in fig. 8 ) by $\mathrm{HB}$ and shows that with an aqueous solution of $\mathrm{Ru}(\mathrm{pzth})_{3}{ }^{2+}$, with $\lambda_{\text {excit }}=337 \mathrm{~nm}$ or $460 \mathrm{~nm}$, the observed emission intensity, at $\lambda_{\text {em. }}=652 \mathrm{~nm}$ will decrease with increasing concentration of HB through an irreversible proton transfer quenching reaction ${ }^{33-35}$.

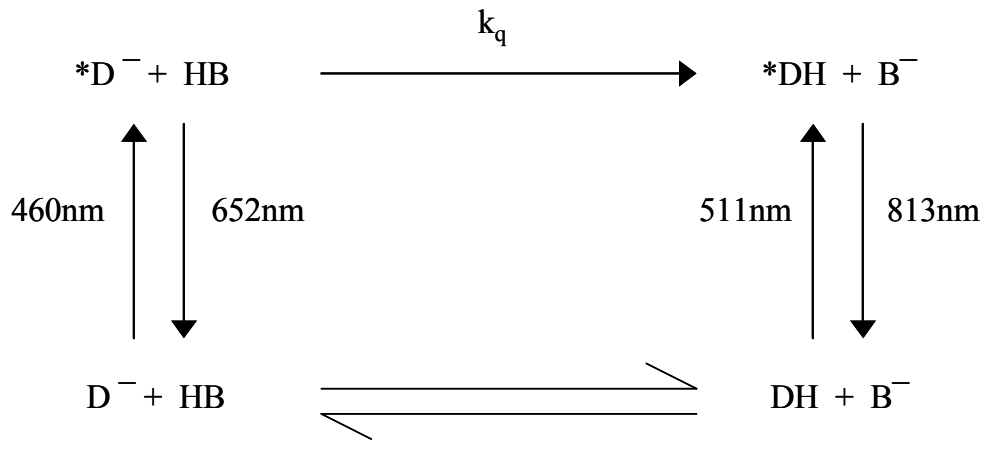

Figure 8. Sensing scheme $\mathrm{e}^{33-35}$ for a carbon dioxide sensor based on the quenching of the luminescence of a dye, $\mathrm{D}^{-}$, where $\mathrm{D}^{-} \equiv \mathrm{Ru}(\mathrm{pzth})_{3}{ }^{2+}$, by a Brönsted acid, HB, where HB = hydrogen pthalate. The vertical up and down arrows refer to the absorption and emission processes associated with $\mathrm{D}^{-}$and $\mathrm{DH}$, the $\lambda_{\max }$ values of which are given next to the arrows and refer to the deprotonated and protonated lumophore $\mathrm{Ru}(\mathrm{pzth})_{3}{ }^{2+}$.

As a consequence of the photochemical properties of $\mathrm{Ru}(\mathrm{pzth})_{3}{ }^{2+}$, illustrated in fig. 8 , Orellana and his co-workers were able to create a novel optical sensor for carbon dioxide comprising: $\mathrm{Ru}(\mathrm{pzth}){ }_{3}{ }^{2+}\left(\mathrm{D}^{-}\right)$immobilised onto CM-Sephadex particles, saturated with 0.1 mol. $\mathrm{dm}^{-3}$ hydrogen phthalate (HB) buffer and covered with a silicone membrane $\mathrm{e}^{33-35}$. This wet optical sensor for carbon dioxide allows the evaluation of $\mathrm{P}_{\mathrm{CO} 2}$ through either lifetime or intensity measurements, as illustrated by the normalised luminescence intensity or emission lifetimes results recorded for this sensor as a function of $\mathrm{P}_{\mathrm{CO} 2}$ profiles in fig. 9, by Orellana and his co-workers ${ }^{35}$.

The sensor is temperature sensitive, as most carbon dioxide optical sensors are, and exhibits a slight sensitivity towards oxygen. Orellana et al also showed ${ }^{34}$ that the addition of the enzyme carbonic anhydrase to the film formulation produced a marked improvement (typically a factor of 3 ) in the response time of the optical sensor by increasing the rate of the forward step in the aquation of carbon dioxide equilibrium step, eqn. (3). Similar observations of the beneficial effects of carbonic anhydrase on the response characteristics of optical sensors for carbon dioxide have also been made by others ${ }^{19}$ working on luminescence-based wet optical sensors for carbon dioxide. 


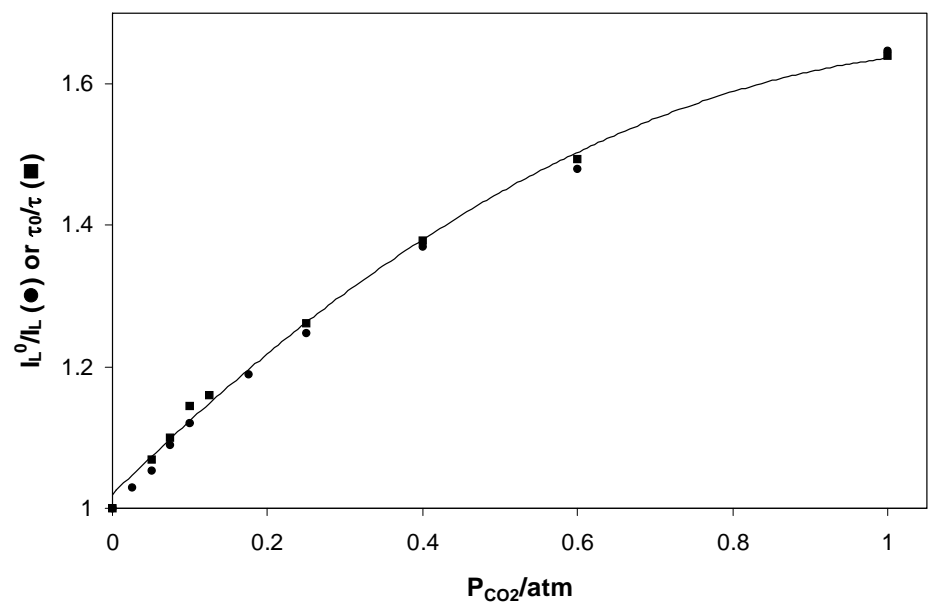

Figure 9. Stern-Volmer plot of the relative luminescence intensity $\left(\mathrm{I}_{\mathrm{L}}{ }^{\circ} / \mathrm{I}_{\mathrm{L}}\right)$ or emission lifetime $\left(\tau_{\mathrm{o}} / \tau\right)$ as a function of $\mathrm{P}_{\mathrm{CO} 2}$ as reported by Orellana et al for their fibre-optic sensor for carbon dioxide. The sensor comprised: $\mathrm{Ru}(\mathrm{pzth})_{3}{ }^{2+}$ immobilised onto $\mathrm{CM}$-Sephadex soaked in a $\mathrm{pH} 7.25$ hydrogen pthalate solution and covered with a silicone gas permeable membrane $\mathrm{e}^{35}$.

The above sensor represents a very novel approach to the luminescence optical sensing of carbon dioxide, although the number of lumophores that have easily measurable lifetimes and are quenched by a proton transfer mechanism still appear very limited, even today.

Interestingly, others have recently promoted ${ }^{42}$ the possibility of generating optical-sensors for carbon dioxide based on the quenching of an excited state by a $\mathrm{pH}$-sensitive quencher. In this case, the quenching process is photoinduced electron transfer in non-aqueous solution between a fluorophore, such as naphthalene and anthracene, and an unprotonated quencher, such as an amine, which is unable, or less efficient, in its quenching ability when protonated. By combining these two features in one molecule, as in 1-naphthylmetylamine (NMA), Herman and his co-workers showed ${ }^{43}$ that the fluorescence of NMA dissolved in dioxane increased when exposed to carbon dioxide. So far only the initial results of experiments conducted in non-aqueous solution have been reported and an optical sensor for carbon dioxide based on this type of process has yet to be generated, despite its apparent promise.

\subsection{Dry Optical Sensors for Carbon Dioxide}

The response characteristics of wet optical sensors for carbon dioxide are altered if the water vapour pressure (for gas phase measurements) or osmotic pressure (for dissolved $\mathrm{CO}_{2}$ measurements) of the system under test is significantly different from that of the sensor. Under the latter circumstances, either some hydration or dehydration of the sensor film will occur upon exposure to the test sample and, as a consequence, the sensor 
will need recalibrating. The latter drawback has long been recognised and effectively restricts the use of such sensors to test and calibrate systems with osmotic, or water vapour, pressure values similar to the wet sensor itself. That is why, for example, Uttamlal and Walt calibrated $^{26}$ the PTFE/HPTS/sodium bicarbonate luminescence based sensor reported earlier in $0.45 \mathrm{M} \mathrm{NaCl}$ solution, so that the calibration medium matched the ionic strength of the fermentation test medium, see fig. 7 . In addition, the same group ${ }^{31,25}$ have noted that such wet optical sensors permanently lose intensity upon prolonged exposure at high $\mathrm{P}_{\mathrm{CO} 2}$ levels and are very slow to respond ( $>30 \mathrm{~min}$ ) at very low $\mathrm{P}_{\mathrm{CO} 2}$ levels. These drawbacks make such wet carbon dioxide sensors far from ideal. The ideal solution to these problems is the Holy Grail of carbon dioxide sensors, namely a solid state device comprising an indicator encapsulated in a gas-permeable, ionimpermeable membrane, with no apparent aqueous solution bicarbonate layer. The key features of such a dry sensor for carbon dioxide are illustrated in fig. 2.

In 1991, Raemer and his co-workers published a patent ${ }^{43}$ on colourimetric carbon dioxide indicators for placement of tracheal tubes, in which it was noted that tetra t-butyl ammonium hydroxide (TBAH), a phase transport agent, 'enhanced the response of the dye'. The agent was thought to accelerate the exchange of carbon dioxide to and from a liquid phase sensor. In this work, the $\mathrm{pH}$-sensitive dye was usually bound to controlled pore glass particles and, most of the sensors that utilised TBAH, gave a reversible response to carbon dioxide. These sensors clearly fall short of the ideal of a 'solid sensor' for carbon dioxide, since they are not encapsulated in a GPM and, therefore, not appropriate for dissolved carbon dioxide work, unless a gas-permeable membrane cover is added. In addition, they are likely to exhibit response features that are markedly affected by changes in humidity (for gas phase work). However, despite these caveats, this patent is notable as one of the first examples of phase transfer agent use in the context of optical sensors for carbon dioxide.

A real advance in solid dry sensor design came with the discovery by others ${ }^{44,45}$ that a phase transfer agent, (PTA), such tetraoctyl ammonium hydroxide (TOAH) or, in its more general form, $\mathrm{Q}^{+} \mathrm{OH}^{-}$, could be used to solubilise the anionic form of a colourimetric $\mathrm{pH}$ indicator dye, such as $m$-cresol purple (MCP), in a hydrophobic solvent, such as toluene, that is mutually compatible with that of a water-insoluble polymer, such as ethyl cellulose (EC) or poly(vinyl butyral), (PVB). Thus, it was found that many PTA's, i.e. $\mathrm{Q}^{+} \mathrm{OH}^{-}$'s, when mixed with a $\mathrm{pH}$ sensitive, hydrophilic indicator dye anion, $\mathrm{D}$, form ion pairs, $\mathrm{Q}^{+} \mathrm{D}^{-}$, that can be dissolved in non-aqueous, and often hydrophobic, solvents in which a variety of different hydrophobic polymers could also be dissolved. The product of such work was effectively a series of coloured inks, comprising: pH-sensitive dye/PTA/ polymer/solvent, which could be cast, by printing, doctor-blade or spin-coating, to generate a range of thin, coloured plastic films containing a $\mathrm{pH}$-sensitive dye in its highly coloured, deprotonated anionic form, i.e. as $\mathrm{Q}^{+} \mathrm{D}^{-}$. Although this formulation goes some way towards generating a solid dry sensor, it is not obvious why the encapsulated ion-paired dye, $\mathrm{Q}^{+} \mathrm{D}^{-}$, would respond to the presence of carbon dioxide. However, it is known that associated with most ion pairs are usually a few molecules of water; thus, the PTA cation, usually a quaternary ammonium cation, $\mathrm{pH}$ - indicator dye anion ion-pair entrapped in a polymer film combination is more appropriately formulated as $\mathrm{Q}^{+} \mathrm{D}^{-} \cdot \mathrm{xH}_{2} \mathrm{O}$. As a consequence, in the final dried ink films, the encapsulated $\mathrm{pH}$-sensitive dye anion, $\mathrm{D}^{-}$, can interact with carbon dioxide as if there is water nearby; and the overall process can be summarised by the following equilibrium process ${ }^{44,45}$ : 


$$
\mathrm{Q}^{+} \mathrm{D}^{-} \cdot x \mathrm{H}_{2} \mathrm{O}+\mathrm{CO}_{2} \stackrel{\alpha}{\Leftrightarrow} \mathrm{Q}^{+} \mathrm{HCO}_{3}^{-} \cdot(x-1) \mathrm{H}_{2} \mathrm{O} \cdot \mathrm{HD}
$$

Where $\alpha$ is the equilibrium constant associated with the process. In order to aid the diffusion of carbon dioxide through the polymer often a plasticiser, such as tributyl phosphate (TBP), is included in the film formulation. Based on this simple formulation, i.e. dye/PTA/plasticiser/polymer/solvent, a number of different colourimetric plastic films were generated by Mills et a ${ }^{37,44-46}$ and others ${ }^{47}$ and all proved very effective as solid-state optical sensors for carbon dioxide.

As you would expect of such solid dry sensors, research reveals that they can be used for the determination of carbon dioxide in dry and humid gase ${ }^{44-47}$ and when dissolved in aqueous solution ${ }^{48}$. These dry films typically exhibit response and recovery times of the order of a few seconds, and very thin films based on this technology, and which respond even faster, i.e. typically $<0.1 \mathrm{~s}$, have been used for capnography ${ }^{49}$. In a dry gas environment it might be expected that such solid film sensors would eventually lose their water of hydration and cease to function. However, the water of hydration associated with the ion-pair combination: PTA cation - $\mathrm{pH}$-sensitive dye anion, appears very tightly bound and as a consequence it appears that these films can be used and stored under very dry conditions without any appreciable loss in performance.

When used for dissolved carbon dioxide measurements these dry optical sensors for carbon dioxide are less sensitive to changes in the osmotic pressures of the samples under test than the wet, i.e. Severinghaus, sensor types discussed so far. Silicone rubber, with its high hydrophobicity and permeability towards carbon dioxide appears a good encapsulation material for such work, although plasticised ethyl cellulose has been used to great effect to create optical sensors for carbon dioxide that can operate over the $\mathrm{pH}$ range 3-10. However, when such dry, ion-pair type carbon dioxide sensors are used for the continuous and prolonged measurement of $\mathrm{P}_{\mathrm{CO} 2}$ in solution then a gas-permeable, ionimpermeable membrane cover is usually required.

Unfortunately, the presence of acidic vapours, such as the dioxides of nitrogen or sulfur, which are often found in the laboratory, have a marked and irreversible deleterious effect on the response features of dry sensors for carbon dioxide. Thus, on the open bench in a laboratory, the dye in the sensor films can change from its deprotonated ( $\left.\mathrm{D}^{-}\right)$ form to its protonated (DH) form, and as consequence become unresponsive, within $24 \mathrm{~h}$. Fortunately, in most environments, the levels of these acidic, oxidising gases are very low and so the shelf life of most ion-pair sensors are usually long ( $>1$ year), especially if placed in sealed bags and stored in the dark; refrigerated conditions also helps to preserve the films.

It has been suggested ${ }^{45}$ that one mode of loss of sensitivity of these ion pair dry sensors for carbon dioxide is the thermal degradation of the phase transfer base through a Hofmann $\beta$-hydrogen elimination reaction. The rather elegant work of Chang et $\mathrm{al}^{50}$ appears to lend support to this proposal, in their study of steam sterilisable fluorescence lifetime-based sensing films for carbon dioxide. Thus, by comparing films containing the same quantity but different quaternary ammonium hydroxides, these workers found that the order of sensor film stability (with number of $\beta$-hydrogens in parenthesis) was: TOAH $(8)<$ CTAH $(2)<$ TMAH $(0)$. The $\mathrm{Q}^{+} \mathrm{D}^{-} \cdot x \mathrm{H}_{2} \mathrm{O}$ ion pairs are so stable when TMAH is used as the PTA that the final films hardly respond at all to carbon dioxide, i.e. the increased ion-pair stability can ultimately affect the key equilibrium process, reaction 
(16). Thus, nowadays CTAH appears the preferred PTA for ion-pair dry sensor films. In order to increase sensor film longevity, most researchers used a vast excess of base, i.e. $\mathrm{Q}^{+} \mathrm{D}^{-} . x \mathrm{H}_{2} \mathrm{O}$, in the film formulation to produce sensors with long operational and storage lifetimes. The excess base in the thin dry film carbon dioxide sensors acts as a lipophilic bicarbonate buffer system and exists in the form of $\mathrm{Q}^{+} \mathrm{HCO}_{3}{ }^{-} \cdot \mathrm{H}_{2} \mathrm{O}$. Increasing the background concentration of the excess base also appears to decrease the sensitivity of the final optical sensor, as it does in its Severinghaus type wet counterpart, see eqn. (9). Table 3 provides details of many of the dry luminescent optical films for carbon dioxide that have been reported in the literature ${ }^{51-70}$ and, as with the wet indicators, reviewed earlier, see table 1, most are intensity- rather than lifetime-, based sensors. Almost all these sensors utilise the ion-pair technology developed by Mills et al ${ }^{44,45}$. Figure 10 gives some of the structures of the key lumophores that are listed in table 3.<smiles>O=S(=O)(O)c1ccc(C2=c3cc4c5c(c3Oc3c2cc2c6c3CCCN6CCC2)CCC[N+]=5CCC4)c(S(=O)(=O)O)c1</smiles>

SRh

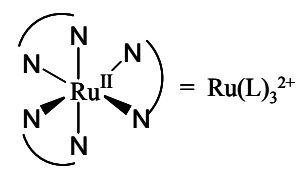<smiles>NCCCN</smiles><smiles></smiles>

4,7-Diphenyl-1,10-phenanthroline (dpp)<smiles>c1ccc(-c2ccnc(-c3ccnc(-c4ccccc4)c3)c2)cc1</smiles>

4,4-Diphenyl-2,2-dipyridyl (dph-bpy)

Figure 10. Structures of some of the key lumophores listed in table 3 and used in dry, ion-pair optical sensors for carbon dioxide. 
Table 3: 'Dry' Luminescent indicator systems for carbon dioxide

\begin{tabular}{|c|c|c|c|c|}
\hline $\begin{array}{c}\text { Luminescent } \\
\text { dye }\end{array}$ & Encapsulating medium & $\begin{array}{l}\text { Gaseous }(\mathrm{g}) \text { or } \\
\text { dissolved }(\mathrm{d})^{*} \mathrm{CO}_{2} \\
\text { measurement }\end{array}$ & $\begin{array}{l}\text { Intensity (I) or } \\
\text { lifetime }(\tau) \\
\text { measurement }\end{array}$ & Ref. \\
\hline Fl & $\begin{array}{l}\text { Polyethylene glycol, } \\
\text { pretrated with sodium } \\
\text { hydroxide }\end{array}$ & $\mathrm{g}$ & I & 51 \\
\hline HPTS & $\begin{array}{l}\text { Dye plus phase transfer } \\
\text { agent, TOAH, in EC } \\
\text { polymer with TBP as a } \\
\text { plasticiser }\end{array}$ & $\mathrm{g}$ & I & 52,37 \\
\hline HPTS & $\begin{array}{l}\text { Dye plus phase transfer } \\
\text { agent (TBAH, MAPTAC } \\
\text { and CTAH) in EC and } \\
\text { polystyrene polymer }\end{array}$ & $\mathrm{g}$ & I & 53 \\
\hline HPTS & $\begin{array}{l}\text { Dye plus phase transfer } \\
\text { agent, TOAH, in EC with } \\
\text { TBP as a plasticiser }\end{array}$ & $\mathrm{d}$ & $\mathrm{I}$ & 54 \\
\hline HPTS & $\begin{array}{l}\text { Dye plus phase transfer } \\
\text { agent, generates HPTS- } \\
\text { CTA }^{+} \text {, with excess } \\
\text { TOAOH, electrostatically } \\
\text { bound to aminocellulose } \\
\text { granules then } \\
\text { encapsulated in silicone } \\
\text { rubber }\end{array}$ & $\mathrm{d}$ & $\mathrm{I}$ & 55 \\
\hline HPTS & $\begin{array}{l}\text { Dye plus phase transfer } \\
\text { agent (TOAH) } \\
\text { encapsulated in an } \\
\text { organically modified } \\
\text { silica glass }\end{array}$ & $\mathrm{g}$ & I & 56,57 \\
\hline$\left[\mathrm{Eu}(\mathrm{tta})_{3}\right]$ & $\begin{array}{l}\text { Luminescence of } \\
\text { europium (II) complex in } \\
\text { polystyrene reduced, by } \\
\text { absorption screening, } \\
\text { using a pH indicator dye } \\
\text { (TB, PR or CR) - TOAH } \\
\text { ion pair, encapsulated in } \\
\text { EC, with TBP as } \\
\text { plasticiser. The two films } \\
\text { were on opposite sides of } \\
\text { the same glass slide. }\end{array}$ & $\mathrm{g}$ & I & $58-60$ \\
\hline
\end{tabular}


Table 3: (Continued)

\begin{tabular}{|c|c|c|c|c|}
\hline $\begin{array}{c}\text { Luminescent } \\
\text { dye }\end{array}$ & Encapsulating medium & $\begin{array}{l}\text { Gaseous }(\mathrm{g}) \text { or } \\
\text { dissolved }(\mathrm{d}) * \mathrm{CO}_{2} \\
\text { measurement }\end{array}$ & $\begin{array}{l}\text { Intensity }(\mathrm{I}) \text { or } \\
\text { lifetime }(\tau) \\
\text { measurement }\end{array}$ & Ref. \\
\hline HPTS & $\begin{array}{l}\text { Dye plus phase transfer } \\
\text { agent, TOAH, in EC } \\
\text { dissolved in } \\
\text { ethanol/toluene solvent. } \\
\text { Viscous solution used in } \\
\text { resevoir-type capillary } \\
\text { optical senor with a PTFE } \\
\text { GPM. }\end{array}$ & $\mathrm{g}$ & $\mathrm{I}$ & 61 \\
\hline HPTS & $\begin{array}{l}\text { Dye plus phase transfer } \\
\text { agent, generates HPTS } \\
\text { CTA }^{+} \text {ion-pair that is then } \\
\text { encapsulated in a silicone } \\
\text { rubber film with an excess } \\
\text { of base, CTAH }\end{array}$ & d & I & 62 \\
\hline HPTS & $\begin{array}{l}\text { Dye immobilized in a } \\
\text { base-catalysed silica sol- } \\
\text { gel by electrostatic } \\
\text { attraction. Sensor film } \\
\text { then covered with a } \\
\text { hydrophobic sol-gel to } \\
\text { reduce pH cross } \\
\text { reactivity. }\end{array}$ & $\mathrm{d}$ & $\mathrm{I}$ & 63 \\
\hline SRh & $\begin{array}{l}\text { Luminescent donor dye, } \\
\text { SR, mixed with a non- } \\
\text { fluorescent acceptor dye } \\
\text { (eg. TB or MCP) with } \\
\text { TOAH, TBP in EC to } \\
\text { produce a plastic film } \\
\text { suitable for FRET }\end{array}$ & $\mathrm{g}$ & $\tau$ & 64,65 \\
\hline $\mathrm{SRh}$ & $\begin{array}{l}\text { SR, plus MCP-CTAH in } \\
\text { silicone rubber creates a } \\
\text { steam-sterilizable sensor. } \\
\text { Detection by FRET. }\end{array}$ & $\mathrm{d}$ & $\tau$ & 50 \\
\hline $\begin{array}{l}\text { Ru(dph- } \\
\text { bpy })_{3}{ }^{2+}:\end{array}$ & $\begin{array}{l}\text { Ru(dph-bpy })_{3}{ }^{2+}-\text { TMS ion } \\
\text { pair plus TB anion }- \\
\text { TMDA }^{+} \text {in an excess of } \\
\text { TOAH encapsulated in } \\
\text { EC was used to prepare } \\
\text { FRET films }\end{array}$ & g & $\tau$ & 66 \\
\hline
\end{tabular}


Table 3: (Continued)

\begin{tabular}{|c|c|c|c|c|}
\hline $\begin{array}{c}\text { Luminescent } \\
\text { dye }\end{array}$ & Encapsulating medium & $\begin{array}{c}\text { Gaseous }(\mathrm{g}) \text { or } \\
\text { dissolved }(\mathrm{d})^{*} \mathrm{CO}_{2} \\
\text { measurement }\end{array}$ & $\begin{array}{l}\text { Intensity }(\mathrm{I}) \text { or } \\
\text { lifetime }(\tau) \\
\text { measurement }\end{array}$ & Ref. \\
\hline $\begin{array}{l}\text { Ru(dph- } \\
\text { bpy })_{3}{ }^{2+}:\end{array}$ & $\begin{array}{l}\text { Ru(dph-bpy })_{3}{ }^{2+}-\text { TMS ion } \\
\text { pair plus MCP anion - } \\
\text { TMDA }{ }^{+} \text {in an excess of } \\
\text { TOAH encapsulated in } \\
\text { EC was used to prepare } \\
\text { FRET films }\end{array}$ & $\mathrm{g}$ & $\tau$ & 67 \\
\hline $\operatorname{Ru}(d p p)_{3}{ }^{2+}$ & $\begin{array}{l}\text { Ru(dpp })_{3}{ }^{2+}-\mathrm{TMS} \text { ion pair } \\
\text { plus Sudan III in an } \\
\text { excess of TOAH } \\
\text { encapsulated in a } \\
\text { hydrophobic silica sol- } \\
\text { gel/EC hybrid produced } \\
\text { films for FRET. }\end{array}$ & $\mathrm{g}$ & $\tau$ & 68 \\
\hline $\operatorname{Ru}(d p p)_{3}{ }^{2+}$ & $\begin{array}{l}\text { Ru(dpp })_{3}{ }^{2+} \text { dye doped } \\
\text { nanobeads provide a } \\
\text { luminescent reference for } \\
\text { the luminescence of } \\
\text { HPTS } \text { CTA }^{+} \text {ion pairs, } \\
\text { all encapsulated in a } \\
\text { hydrophobic organically } \\
\text { modified silica film. } \\
\text { Basis of sensing via DLR. }\end{array}$ & g & $\tau$ & 69 \\
\hline
\end{tabular}

A luminescence intensity-based dry optical sensor film for carbon dioxide which used the phase transfer technology discussed above was reported ${ }^{37}$ as early as 1993 . In this work, the dye used was HPTS, the phase transfer agent, TOAH, the polymer, EC, and the plasticiser, TBP. In such a system, assuming eqn (16) is the key equilibrium process, then a new parameter, $\mathrm{R}$, can be defined as follows:

$$
\mathrm{R}=\left(\mathrm{I}_{\mathrm{L}}{ }^{\mathrm{o}}-\mathrm{I}_{\mathrm{L}}\right) / \mathrm{I}_{\mathrm{L}}=\alpha \cdot \mathrm{P}_{\mathrm{CO} 2}
$$

Where, $\mathrm{I}_{\mathrm{L}}{ }^{\circ}$ and $\mathrm{I}_{\mathrm{L}}$ are the luminescence intensities of $\mathrm{Q}^{+} \mathrm{D}^{-} \cdot x \mathrm{H}_{2} \mathrm{O}$ in the absence and presence of carbon dioxide, respectively. Given the similar natures of the two processes, it is not surprising to note that the wet and dry luminescence intensity-based optical sensors have very similar key equations, i.e. eqns. (10) and (17), respectively. As with eqn. (10), eqn. (17) assumes that an excitation wavelength is selected at which only $\mathrm{Q}^{+} \mathrm{D}^{-} . x \mathrm{H}_{2} \mathrm{O}$ absorbs, and that in the absence of carbon dioxide all the dye will be in its anionic form. The spectral properties of the first reported HPTS/TOAH/EC/TBP sensor film for carbon dioxide are given ${ }^{37}$ in table 2 . Thus, the absorption and emission spectra of the protonated and deprotonated forms of HPTS in the plastic film are very similar to those of the dye in aqueous solution, although shifted slightly in a bathochromic direction. This shift is due mainly to the formation of the quaternary ammonium cation- 
dye anion ion pairs, and, to some extent, to the change in the polarity of the surrounding environment.

A typical example of the observed variation in luminescence intensity, measured at $517 \mathrm{~nm}$ and due to the deprotonated form of HPTS in a HPTS/TOAH/EC/TBP film, as a function of the partial pressure of carbon dioxide in the test medium, is illustrated ${ }^{37}$ in fig. 11. The subsequent plot of this data in the form of $R\left(=\left(I_{L}{ }^{0}-I_{L}\right) / I_{L}\right)$ vs. $P_{C O 2}$ is illustrated in the insert diagram in fig. 11 and reveals a reasonable straight line as predicted by eqn (17). As noted earlier, in aqueous solution the excited state of the protonated form of HPTS, i.e. DH*, emits the green light $\left(\lambda_{\max }=512 \mathrm{~nm}\right)$ associated with the excited state of the deprotonated form of the dye, i.e. $\mathrm{Q}^{+} \mathrm{D}^{*}$ (see fig. 2). This phenomenon is due to the very rapid equilibrium between $\mathrm{DH}^{*}$ and $\mathrm{D}^{-*}$ and $\mathrm{H}^{+}$in solution. However, in a solid film this equilibrium does not appear to be so well established ${ }^{37}$ and emission from $\mathrm{DH}^{*}$, or more precisely $\mathrm{Q}^{+} \mathrm{HCO}_{3}^{-}$. $(x-1) \cdot \mathrm{H}_{2} \mathrm{O} \cdot \mathrm{HD}$ at $440 \mathrm{~nm}$ is observed in a HPTS/TOAH/EC/TBP film at high $\mathrm{P}_{\mathrm{CO} 2}$ levels.

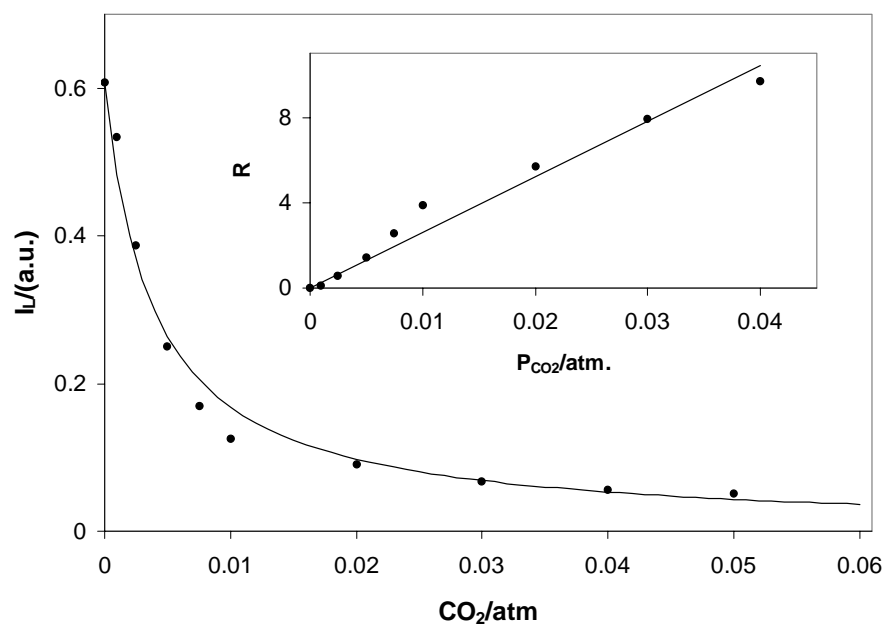

Figure 11. Reported ${ }^{37}$ variation in the observed luminescence intensity of a HPTS/TOAH/EC/TBP dry film sensor as a fuction of $\mathrm{P}_{\mathrm{CO} 2}$, recorded using $\lambda_{\text {excit. }}=430 \mathrm{~nm}$ and $\lambda_{\mathrm{em}}=517 \mathrm{~nm}$. The insert diagram is a replot of the data in the main diagram, where $\mathrm{R}$ is defined by eqn. (17).

A number of other researchers, see table 3, have subsequently used HPTS, coupled with a PTA, encapsulated in a polymer, such as EC or silicone rubber, to create similar luminescence intensity-based optical sensors for carbon dioxide. Probably the most notable of these is the high-stability, non-invasive auctoclavable naked optical sensor for dissolved carbon dioxide measurement reported by Rao et $\mathrm{al}^{62}$. The sensor film comprises: HPTS/CTAH/RTV-silicone rubber; the latter being chosen because of its highly hydrophobic nature. This sensor has a shelf life of several months and exhibits no cross-sensitivity to salt in the range $0-0.2 \mathrm{M}$, or to $\mathrm{pH}$, in the range $5.6-8.0$, despite the 
fact that no gas-permeable membrane cover layer was used. The latter feature explains the use of the term 'naked' in the paper's title ${ }^{62}$. The robustness of this sensor film towards ion-exchange, and heat treatment (it's autoclavable) is due to the robust and hydrophobic nature of the encapsulation polymer employed. Typical plots of the normalised emission, and excitation, spectra exhibited by this HPTS/CTAH/silicone rubber film recorded ${ }^{62}$ for this film for dissolved carbon dioxide concentrations ranging from $0-18.15 \%$ are illustrated in fig. 12 . Interestingly, the optical characteristics of HPTS $^{-}$in this film, and its response toward carbon dioxide, are much like they are for the dye in aqueous solution, i.e. there is no evidence that $\mathrm{DH}^{*}$ is stable and not readily dissociated in this film, unlike the HPTS/TOAH/EC films discussed earlier.

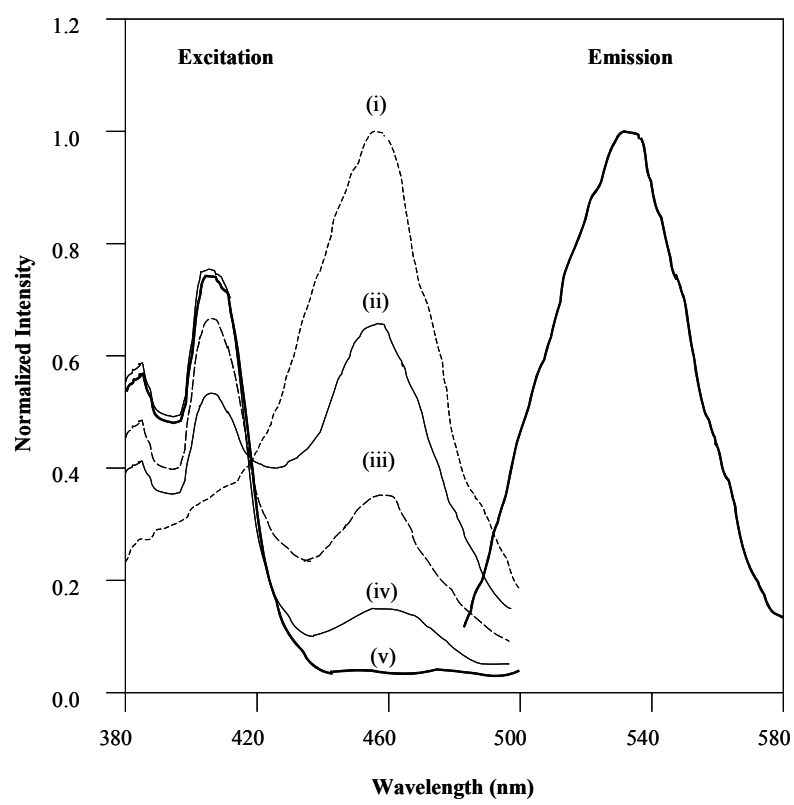

Figure 12. Normalised reported ${ }^{62}$ excitation and emission spectra of a naked, i.e. no GPM cover, HPTS/silicone rubber film when exposed to water purged with the following levels of carbon dioxide: (i) 0, (ii) 0.13 , (iii) 0.37 , (iv) 0.58 and $18.15 \%$.

Continuing the theme of novel encapsulating media, a dry optical sensor for carbon dioxide, employing the HPTS-tetraoctyl ammonium cation ion pair has been developed ${ }^{56}$ which uses an organically modified silica glass (ormosil), rather than an organic polymer, as an encapsulation medium. In this study a relatively high humidity was maintained in all test and sample gases, since work showed the dry luminescent sensor film to be quite sensitive towards variations in humidity. The latter feature, largely absent from plastic film based sensors, appears a possible drawback to the use of ormosil in dry optical sensors for carbon dioxide.

To summarise at this point, most of the luminescence intensity-based dry optical sensors for carbon dioxide listed in table 3 work on similar principles as their wet optical 
sensor counterparts. Thus, these sensors utilise a $\mathrm{pH}$-sensitive, luminescent dye, such as HTPS, encapsulated in a polymer in its anionic form using a phase transfer agent. The key equations that describe the interaction of the dye with carbon dioxide in the test medium are (16) and (17), in which it is assumed that a wavelength of excitation, $\lambda_{\text {excit }}$, is chosen so that only the anionic form of the dye absorbs and that the measured intensity of luminescence, $\mathrm{I}_{\mathrm{L}}$, is due only to $\mathrm{D}^{*}$.

A different type of luminescence intensity-based dry optical sensor for carbon dioxide has been reported recently by Nakamura and $A m a o^{58-60}$, using a combination of a luminescent europium (II) complex, $\left[\mathrm{Eu}(\mathrm{tta})_{3}\right]$, and a $\mathrm{pH}$-sensitive colourimetric dye, such as TB, PR or CR. As with almost all dry indicator systems for carbon dioxide, the $\mathrm{pH}$-sensitive dyes used are always in the form of an ion pair, i.e. $\mathrm{Q}^{+} \mathrm{D}^{-} x \mathrm{H}_{2} \mathrm{O}$. In this work, TOAH was used as the PTA, EC as the encapsulation polymer and TBP as the plasticiser. This indicator is, in effect, a simple, standard colourimetric dry indicator for carbon dioxide, with the added exception to its formulation of a fluorophore, [Eu(tta) $)_{3}$, which is not quenched by FRET and has an absorption spectrum that overlaps with that of the anionic form of the non-luminescent, $\mathrm{pH}$-sensitive dye, $\mathrm{Q}^{+} \mathrm{D}^{-} \cdot x \mathrm{H}_{2} \mathrm{O}$. As a consequence, as the level of $\mathrm{P}_{\mathrm{CO} 2}$ in the test medium is increased, the intensity of luminescence due to $\left[\mathrm{Eu}(\mathrm{tta})_{3}\right]$ will increase, because the concentration of $\mathrm{Q}^{+} \mathrm{D}^{-} . x \mathrm{H}_{2} \mathrm{O}$ decreases and so, therefore, does its absorbance at $\lambda_{\text {excit }}$. Such a decrease in absorbance allows more of the excitation light to be absorbed by the lumophore, [Eu(tta) $\left.{ }_{3}\right]$, and, therefore, the luminescence of the latter will increase intensity, the higher the level of $\mathrm{P}_{\mathrm{CO} 2}$. Typical results generated ${ }^{58}$ by three such $\mathrm{pH}$-intensive lumophore/pH-sensitive colourimetric dye type sensors, namely: $\left[\mathrm{Eu}(\mathrm{tta})_{3}\right] / \mathrm{TB} / \mathrm{TOAH} / \mathrm{EC} / \mathrm{TBP}$, $\left[\mathrm{Eu}(\mathrm{tta})_{3}\right] / \mathrm{PR} / \mathrm{TOAH} / \mathrm{EC} / \mathrm{TBP}$ and $\left[\mathrm{Eu}(\mathrm{tta})_{3}\right] / \mathrm{CR} / \mathrm{TOAH} / \mathrm{EC} / \mathrm{TBP}$, are illustrated in figure 13. For this system it can be shown, via eqn.(16), that the concentration of the protonated $\mathrm{pH}$-sensitive dye, i.e. $\left[\mathrm{Q}^{+} \mathrm{HCO}_{3}^{-} \cdot(x-1) \mathrm{H}_{2} \mathrm{O} . \mathrm{DH}\right]$, is related to $\mathrm{P}_{\mathrm{CO} 2}$ via the expression:

$$
\left[\mathrm{Q}^{+} \mathrm{HCO}_{3 \cdot}^{-} \cdot(x-1) \mathrm{H}_{2} \mathrm{O} \cdot \mathrm{DH}\right]=\frac{[\mathrm{D}]_{\mathrm{TOTAL}} \alpha \mathrm{P}_{\mathrm{CO} 2}}{1+\alpha \mathrm{P}_{\mathrm{CO} 2}}
$$

where $[\mathrm{D}]_{\text {TOTAL }}$ is the total concentration of the colourimetric, ion-paired $\mathrm{pH}$-sensitive dye in the film, i.e. $[\mathrm{D}]_{\text {TоTAL }}=\left[\mathrm{Q}^{+} \mathrm{HCO}_{3}^{-} \cdot(x-1) \mathrm{H}_{2} \mathrm{O} \cdot \mathrm{DH}\right]+\left[\mathrm{Q}^{+} \mathrm{D}^{-} \cdot x \mathrm{H}_{2} \mathrm{O}\right]$. In the work of Nakamura et al, on these $\left[\mathrm{Eu}(\mathrm{tta})_{3}\right] / \mathrm{pH}$-sensitive dye films, the intensity of luminescence of $\left[\mathrm{Eu}(\mathrm{tta})_{3}\right]$ appears proportional to $\left[\mathrm{Q}^{+} \mathrm{HCO}_{3}^{-} .(x-1) \mathrm{H}_{2} \mathrm{O} . \mathrm{DH}\right]$, although this is only expected for optically dilute systems, which these are probably not. However, given this apparent relationship, it follows that, $\mathrm{I}_{\mathrm{L}}$ is related to $\mathrm{P}_{\mathrm{CO} 2}$ via the following expression:

$$
\frac{\mathrm{I}_{\mathrm{L}}-\mathrm{I}_{\mathrm{L}}^{\circ}}{\mathrm{I}_{\mathrm{L}}^{100}-\mathrm{I}_{\mathrm{L}}^{\circ}}=\frac{\mathrm{KP}_{\mathrm{CO} 2}}{1+\alpha \mathrm{P}_{\mathrm{CO} 2}}
$$

$\mathrm{I}_{\mathrm{L}}{ }^{\circ}$ and $\mathrm{I}_{\mathrm{L}}{ }^{100}$ are the intensities of luminescence of this type of film at 0 and $100 \% \mathrm{CO}_{2}$, respectively, and where $\mathrm{K}$ is a constant. It follows from eqn. (19) that the data illustrated in fig. 13 for this type of optical sensor can be linearised by plotting $\left(\mathrm{I}_{\mathrm{L}}{ }^{100}-\mathrm{I}_{\mathrm{L}}{ }^{\circ}\right) /\left(\mathrm{I}_{\mathrm{L}}-\mathrm{I}_{\mathrm{L}}{ }^{\circ}\right)$ versus $\mathrm{P}_{\mathrm{CO} 2}{ }^{-1}$, as reported by Nakamura et $\mathrm{al}^{58}$. Like the wet FRET sensors described earlier, this type of optical sensor, described as 'colourimetric with a reference 
luminescent dye', overcomes the problem of the limited availability of fluorescent $\mathrm{pH}$-sensitive dyes with $\mathrm{pK}_{\mathrm{a}}$ values that span a wide $\mathrm{pH}$ range. Instead, unlike the FRET-based carbon dioxide sensors, this type of sensor requires only a luminescent dye which has an absorption spectrum that's similar to that of one of the forms of the $\mathrm{pH}$-sensitive, colourimetric dye. Usually, this absorption spectral overlap is between the $\mathrm{pH}$-insensitive fluorophore and the anionic form of the $\mathrm{pH}$ colourimetric dye. As with the FRET-type sensors, the possible combinations of $\mathrm{pH}$-insensitive fluorophore and pH-colourimetric dye are many. However, it is not clear what benefits this luminescence intensity-based sensor offers over its simpler, colourimetric counterpart, which has the same formulation, with the exception of the lumophore, other than it allows the measurement of $\mathrm{P}_{\mathrm{CO} 2}$ via luminescence intensity, rather than absorbance, measurements.

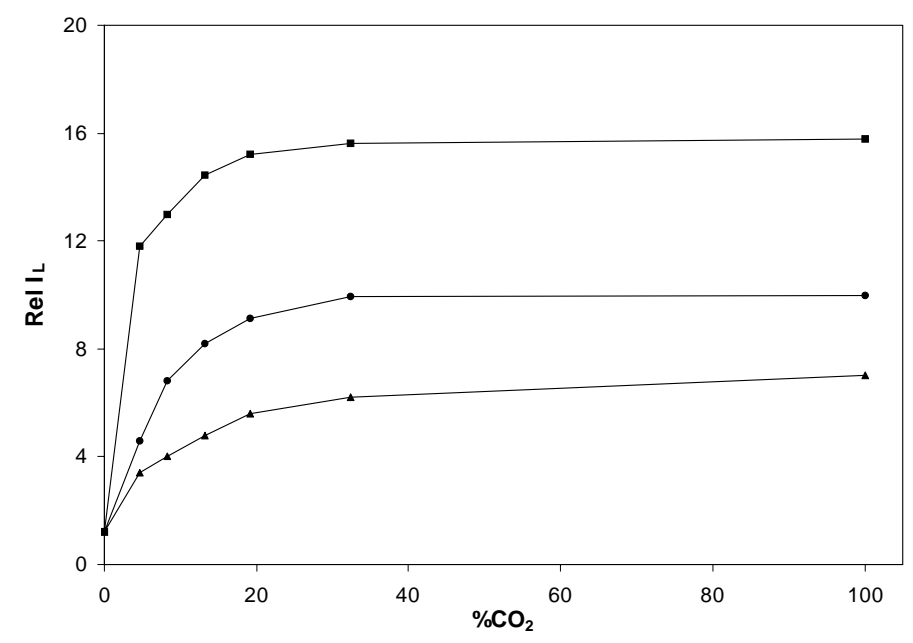

Figure 13. Observed ${ }^{58}$ variation in the relative intensity of luminescence as a function of $\mathrm{P}_{\mathrm{CO} 2}$ for three different dry 'colourimetric with reference luminescent dye' type sensors. The three different sensors used comprised: the lumophore $\left[\mathrm{Eu}(\mathrm{tta})_{3}\right], \mathrm{EC} / \mathrm{TBP}$ and the following three different $\mathrm{pH}$-sensitive colourimetric dyes: TB ( $\bullet)$, PR (•) or CR ( $\bullet$ ). The results of this work can be linearised using eqn. (19).

As early as 1995 , researchers ${ }^{64}$ began to report FRET-based dry optical sensors for carbon dioxide. The features of such sensors, namely a fluorescent, $\mathrm{pH}$-insensitive donor (D) and a colourimetric $\mathrm{pH}$-sensitive acceptor (A), with a great deal of overlap between the emission spectrum of $\mathrm{D}$ and the absorption spectrum of $\mathrm{A}$, were much like those noted earlier for wet type, FRET-based sensors, with the exception that the $\mathrm{pH}$-sensitive dye was combined with a PTA to render it soluble in a hydrophobic medium, such as a polymer. Thus, for example, Sipior and co-workers ${ }^{64}$ in their 1995 study of dry, FRET-based optical sensors for carbon dioxide used, amongst others, the luminescent dye sulforhodamine (SR) as the donor and a thymol blue (TB)-TOAH ion-pair as the acceptor; all entrapped in an ethyl cellulose polymer matrix. The frequency responses of this SR/TB-TOAH/EC film as a function of the level of carbon dioxide in a test humid 
nitrogen gas-phase medium are illustrated in fig. 14(a), for which only the reported phase shift data for this system are illustrated. A plot of this data, recorded at a frequency of $138.14 \mathrm{MHz}$ in the form of phase angle, $\phi$, versus $\% \mathrm{CO}_{2}$ is illustrated in fig. 14 (b). In such sensors the lifetime of the lumophore is at a maximum, $\tau_{\max }$, when there is no FRET, i.e. when all the $\mathrm{pH}$-sensitive dye is protonated due to a high level of carbon dioxide in the test medium.

It follows that:

$$
\frac{\tau_{\max }}{\tau}=\frac{\mathrm{k}_{\mathrm{other}}+\mathrm{k}_{\mathrm{FRET}}}{\mathrm{k}_{\mathrm{other}}}
$$

where $\mathrm{k}_{\mathrm{FRET}}$ is the rate of fluorescence resonance energy transfer and $\mathrm{k}_{\mathrm{other}}$ is the rate constant for all other deactivations, including luminescence. Since $\mathrm{k}_{\mathrm{FRET}}$ will be proportional to the concentration of the deprotonated $\mathrm{pH}$-sensitive dye, i.e. $\left[\mathrm{Q}^{+} \mathrm{D}^{-} . \mathrm{H}_{2} \mathrm{O}\right]$, then,

$$
\frac{\tau_{\max }}{\tau}-1=\frac{\mathrm{k}_{\text {FRET }}}{\mathrm{k}_{\text {other }}}=\mathrm{K}^{\prime}\left[\mathrm{Q}^{+} \mathrm{D}^{-} . x \mathrm{H}_{2} \mathrm{O}\right]
$$

where $\mathrm{K}^{\prime}$ is a proportionality constant. However, from eqn. (16) it can be shown that:

$$
\alpha \mathrm{P}_{\mathrm{CO} 2}=\frac{\left[\mathrm{Q}^{+} \mathrm{D}^{-} \cdot x \mathrm{H}_{2} \mathrm{O}\right]_{\mathrm{o}}-\left[\mathrm{Q}^{+} \mathrm{D}^{-} \cdot x \mathrm{H}_{2} \mathrm{O}\right]}{\left[\mathrm{Q}^{+} \mathrm{D}^{-} \cdot x \mathrm{H}_{2} \mathrm{O}\right]}
$$

where $\left[\mathrm{Q}^{+} \mathrm{D}^{-} \cdot x \mathrm{H}_{2} \mathrm{O}\right]_{\mathrm{o}}$ is the concentration of $\left[\mathrm{Q}^{+} \mathrm{D}^{-} \cdot x \mathrm{H}_{2} \mathrm{O}\right]$ when no carbon dioxide is present and all the $\mathrm{pH}$-sensitive dye is in its deprotonated, ion-paired form. Combining eqns. (21) and (22) together the following expression can be derived:

$$
\frac{\left(\tau_{\max } / \tau_{\mathrm{o}}-1\right)-\left(\tau_{\max } / \tau-1\right)}{\left(\tau_{\max } / \tau-1\right)}=\alpha \mathrm{P}_{\mathrm{CO} 2}
$$

where $\tau_{\mathrm{o}}$ and $\tau$ are the lifetimes of the donor lumophore in the absence and presence of carbon dioxide.

or, more simply:

$$
\frac{\left(1 / \tau_{\mathrm{o}}-1 / \tau\right)}{\left(1 / \tau-1 / \tau_{\max }\right)}=\mathrm{R}=\alpha \mathrm{P}_{\mathrm{CO} 2}
$$




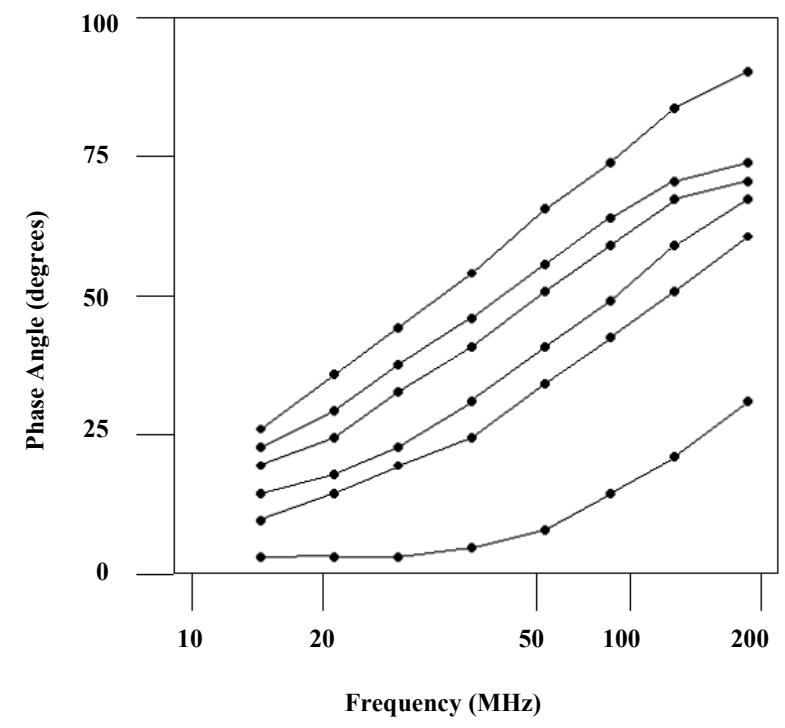

(a)

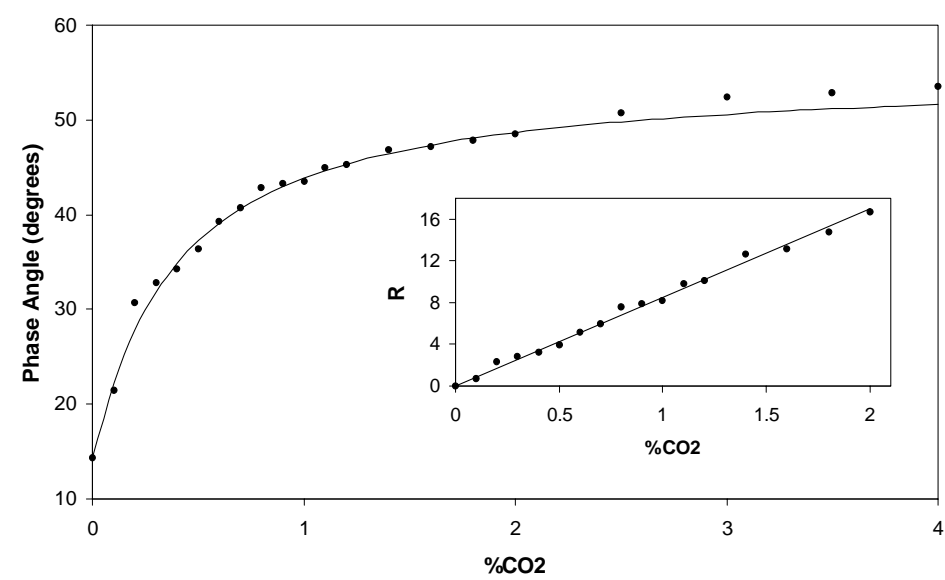

(b)

Figure 14. (a) Observed variation in phase angle, $\phi$, as a function of modulation frequency for an SR/TB-TOAH/EC dry sensor film. The different profiles are the film responses when exposed to the following different levels of carbon dioxide (from top to bottom): $\infty, 10,2,0.5,0.25$ and $0 \%$. The ' $\infty$ ' $\mathrm{CO}_{2}$ response curve was recorded for a sensor film without any TB-TOAH ion pair, i.e. for SR alone ${ }^{64}$.(b) Observed variation in phase angle as a function of $\% \mathrm{CO}_{2}$, for the SR/TB-TOAH/EC film sensor used in (a), using $442 \mathrm{~nm}$ light modulated at a frequency of $138.14 \mathrm{MHz}$. The insert diagram is the linearised plot of the data in the main diagram, where the function of $\mathrm{R}$ is defined by eqn. (25), assuming $\phi_{0}$ and $\phi_{\max }$ are equal to 14.3 and $55^{\circ}$, respectively ${ }^{64}$. 
In the work of Sipior et $\mathrm{al}^{64}$, and all FRET-based dry optical sensors for carbon dioxide, a phase modulation technique was used to measure the lifetime of the $\mathrm{pH}$-insensitive donor lumophore. As a consequence, it is more relevant and useful to rewrite eqn. (24) with respect to the measured phase angle, given eqn. (13). Thus, eqn. (24) can be more usefully written as:

$$
\frac{\left(\cot \phi_{\mathrm{o}}-\cot \phi\right)}{\left(\cot \phi-\cot \phi_{\max }\right)}=\mathrm{R}=\alpha \mathrm{P}_{\mathrm{CO} 2}
$$

where $\mathrm{R}$ is a parameter that can be easily calculated, using eqn. (25) and $\phi_{0}, \phi$ and $\phi_{\max }$ which are the measured phase angles for the sensing system in the absence, presence and overwhelming presence (so that all the $\mathrm{pH}$-sensitive dye is protonated) of carbon dioxide. The insert diagram in fig. 14(b) illustrates the plot of the data in the main diagram, taken from the work of Sipior et $\mathrm{al}^{64}$ for their SR/TB-TOAH/EC films, in the form of $\mathrm{R}$ vs. $\% \mathrm{CO}_{2}$, where $\mathrm{R}$ is defined by eqn. (25). The linearity of this plot helps confirm the validity of eqn. (25) and the underlying assumption that the degree of FRET quenching is proportional to $\left[\mathrm{Q}^{+} \mathrm{D}^{-} \cdot x \mathrm{H}_{2} \mathrm{O}\right]$.

As noted earlier, a major problem with FRET, as a method for interrogating optical sensors, such as FRET-based wet, or dry, optical sensors for carbon dioxide, is the need for expensive equipment. It is the short lifetime, typically $0.5-5 \mathrm{~ns}$, of the donor lumophores that are usually used in such sensors that make it necessary to use expensive optical sources, such as lasers, frequency generators, optics and electronics. In an attempt to address this problem, Klimant and his co-workers ${ }^{66}$ developed a Ru(dphbpy $)_{3}{ }^{2+}-(\mathrm{TMS})_{2} / \mathrm{MCP}^{-} \mathrm{TMDA}^{+} / \mathrm{EC}$ film sensor for carbon dioxide that required a much less expensive lifetime measuring system. These workers used the ion pair technique to both solubilise the anionic form of the $\mathrm{pH}$-sensitive colourimetric acceptor dye, and the cationic donor lumophore $\mathrm{Ru}(\mathrm{dph}-\mathrm{bpy})_{3}{ }^{2+}$. Thus, the $\mathrm{pH}$-sensitive acceptor $\mathrm{MCP}^{-}$and the $\mathrm{pH}$-insensitive, long-lived donor $\mathrm{Ru}(\mathrm{dph}-\mathrm{bpy})_{3}{ }^{2+}$ were rendered lipophilic, and therefore soluble in the EC supporting polymer, using the lipophilic cation and anions, TMDA ${ }^{+}$ and $\mathrm{TMS}^{-}$, respectively. An excess of TOAH was also added to the film formulation in order to ensure prolonged functionality. Klimant and his co-workers ${ }^{66}$ chose to use a donor with a long lifetime, $>1 \mu \mathrm{s}$, since it enabled lifetime measurements to be performed on this FRET-based optical sensor for carbon dioxide using just a bright blue light emitting diode (LED), $\lambda_{\max }$ (emission) $=470 \mathrm{~nm}$, operating at a frequency of only 75 $\mathrm{kHz}$; making it much cheaper than the high frequency, laser-based phase modulation lifetime measuring systems used previously in such work. Using this inexpensive frequency domain fluorescence spectroscopy system to determine the lifetime of the lumophore in the $\mathrm{Ru}(\mathrm{dph}-\mathrm{bpy})_{3}{ }^{2+}-\left(\mathrm{TMS}^{-}\right)_{2} / \mathrm{MCP}^{-}-\mathrm{TMDA}^{+} / \mathrm{TOAH} / \mathrm{EC}$ dry film sensor, as a function of $\mathrm{P}_{\mathrm{CO} 2}$, Klimant et al found $\tau$ to vary as a function of $\mathrm{P}_{\mathrm{CO} 2}$ as illustrated ${ }^{66}$ in fig. 15. Once again this data can be linearised using eqn. (24) for a FRET-based optical sensor for carbon dioxide as illustrated by the insert diagram in fig. 15. More recently, McCraith and his co-workers ${ }^{68}$ have reported a $\mathrm{Ru}(\mathrm{dpp})_{3}{ }^{2+}-\left(\mathrm{TMS}^{-}\right) 2 /$ Sudan (III) TOAH/(silica sol-gel/EC) dry FRET-based optical sensor for carbon dioxide that used the same bright blue LED as used by Klimant et al but operated at only $20 \mathrm{kH}$. Because of the high $\mathrm{pK}_{\mathrm{a}}$ of Sudan (III), McCraith et al were able to operate their dry, FRET-based carbon dioxide sensors up to $\mathrm{P}_{\mathrm{CO} 2}$ levels of $1 \mathrm{~atm}$. Thus, from these two examples, it is 
clear that it is possible to devised FRET-based sensors for carbon dioxide that require relatively low frequency, i.e. $\quad<100 \mathrm{MHz}$, modulated excitation light generation and detection, which are much more affordable.

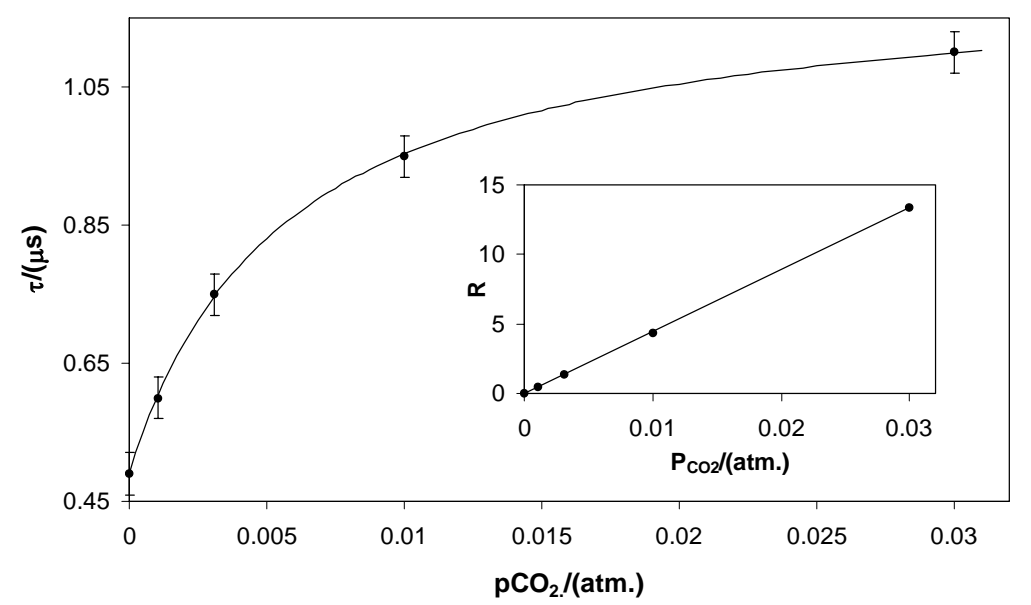

Figure 15. Observed ${ }^{66}$ variation in luminescence lifetime, for a $\mathrm{Ru}(\mathrm{dph}-\mathrm{bpy})_{3}{ }^{2+}-(\mathrm{TMS})_{2}^{-} / \mathrm{MCP}^{-}$ $\mathrm{TMDA}^{+} / \mathrm{TOAH} / \mathrm{EC}$ FRET-based film sensor as a function of $\mathrm{P}_{\mathrm{CO} 2}$. The lifetime data were determined using a phase-modulated blue LED excitation source $\left(\lambda_{\text {ex. }}=470 \mathrm{~nm}\right)$ and a red-sensitive PMT $\left(\lambda_{\text {em(max })}=630 \mathrm{~nm}\right)$. The insert diagram is a linearised plot of the lifetime data in the main diagram, where the parameter $\mathrm{R}$ has been calculated for each value of $\mathrm{P}_{\mathrm{CO} 2}$ using eqn. (24) and $\tau_{\mathrm{o}}$ and $\tau_{\max }=0.49$ and $1.21 \mu \mathrm{s}$, respectively.

A brief inspection of the many examples of dry luminescent indicator systems for carbon dioxide reveals that most of those reported to date are intensity-based and, amongst the few other, and admittedly more recent, examples, the FRET method of detection dominates. One other sensing method that doesn't fall into any of the categories considered so far, is the measurement of carbon dioxide levels using phasemodulated fluorimetry coupled with a Dual Lumophore Referencing (DLR) proposed by MacCraith et $\mathrm{al}^{69}$. In DLR, two different luminescence signals are generated in the sensing membrane by the modulated excitating light source; in this case a bright blue 470 $\mathrm{nm}$ LED. In DLR, the two lumophores must have a significant overlap in their excitation and emission spectra, so that both luminescence signals can be excited by one light source (the modulated LED) and detected by one filter-detector combination. As a consequence of this combination, it follows that the total signal is a superposition of the two signals. However, one of the lumophores is selected so that it is $\mathrm{pH}$, and therefore $\mathrm{P}_{\mathrm{CO} 2}$, insensitive and has a lifetime that is similar to that of $1 / f$ where $f=$ frequency of the modulated excitation light; this is referred to as the reference lumophore. The other lumophore is selected on the basis that it is $\mathrm{pH}$, and therefore $\mathrm{P}_{\mathrm{CO} 2}$, sensitive and has a 
lifetime that is so short that the phase shift is zero; this is referred to as the analyte lumophore. In the work of McCraith et $\mathrm{al}^{69}$ the reference lumophore was $\mathrm{Ru}(\mathrm{dpp})_{3}{ }^{2+}$ doped nano-beads and the analyte lumophore was HPTS ion-paired with CTMAH to render it soluble in the hydrophobic organically-modified silica encapsulation matrix used in this work. In such a system the intensity of luminescence due to the reference lumophore, $\mathrm{I}_{\mathrm{L}(\mathrm{REF})}$, is given by:

$$
\mathrm{I}_{\mathrm{L}(\mathrm{REF})}=\mathrm{I}_{\mathrm{B} 1}+\mathrm{I}_{\mathrm{REF}} \sin \left(\mathrm{wt}+\phi_{\mathrm{REF}}\right)
$$

where $I_{B 1}$ and $I_{R E F}$ are the background and amplitude luminescence intensities due to the reference lumophore in the optical film subjected to an excitation light of angular frequency $\omega$ and producing a fixed phase shift, $\phi_{\mathrm{REF}}$. For the analyte lumophore, HPTS in this case, which has a very short lifetime, (i.e. $\tau_{\text {analyte }}<<2 \pi / \omega$, i.e. $\phi_{\text {analyte }}=0$, the variation in the intensity of luminescence due to the analyte lumophore, is, as a consequence, given by the following expression:

$$
\mathrm{I}_{\mathrm{L}(\mathrm{HPTS})}=\mathrm{I}_{\mathrm{B} 2}+\mathrm{I}_{\mathrm{HPTS}} \sin (\omega \mathrm{t})
$$

It follows that:

$$
\mathrm{I}_{\mathrm{L}}(\text { total })=\mathrm{I}_{\mathrm{B}}(\text { total })+\mathrm{I}_{\mathrm{REF}} \sin \left(\omega \mathrm{t}+\phi_{\mathrm{REF}}\right)+\mathrm{I}_{\mathrm{HPTS}} \sin (\omega \mathrm{t})
$$

where $\mathrm{I}_{\mathrm{L}}$ (total) is the total background luminescence light intensity $=\mathrm{I}_{\mathrm{B} 1}+\mathrm{I}_{\mathrm{B} 2}$. Using the mathematic expression: $\sin (\mathrm{v}+\mathrm{u})=\sin (\mathrm{v}) \cos (\mathrm{u})+\cos (\mathrm{v}) \sin (\mathrm{u})$, it follows that:

$$
\sin \left(\omega t+\phi_{\mathrm{REF}}\right)=\sin (\omega \mathrm{t}) \cos \left(\phi_{\mathrm{REF}}\right)+\cos \omega \mathrm{t} \sin \left(\phi_{\mathrm{REF}}\right)
$$

thus

$$
\begin{aligned}
\mathrm{I}_{\mathrm{REF}} \sin \left(\omega \mathrm{t}+\phi_{\mathrm{REF}}\right)+\mathrm{I}_{\mathrm{HPTS}} \sin (\omega \mathrm{t})= & \sin (\omega \mathrm{t})\left(\mathrm{I}_{\mathrm{HPTS}}+\mathrm{I}_{\mathrm{REF}} \cos \left(\phi_{\mathrm{REF}}\right)\right)+ \\
& \cos (\omega \mathrm{t})\left(\mathrm{I}_{\mathrm{REF}} \sin \left(\phi_{\mathrm{REF}}\right)\right)
\end{aligned}
$$

But, using the previous mathematical expression it can be shown that:

$$
C \sin (\omega t)+D \cos (\omega t)=M \sin \left(\omega t+\phi_{M}\right)
$$

where $C=M \cos \left(\phi_{M}\right)$ and $D=M \sin \left(\phi_{M}\right)$ and $M=\left(C^{2}+D^{2}\right)^{1 / 2}$. Comparing eqns. (31) with (30) it follows therefore:

$$
\mathrm{I}_{\mathrm{REF}} \sin \left(\omega \mathrm{t}+\phi_{\mathrm{REF}}\right)+\mathrm{I}_{\mathrm{HPTS}} \sin (\omega \mathrm{t})=\mathrm{M} \sin \left(\omega \mathrm{t}+\phi_{\mathrm{M}}\right)
$$

where

$$
\mathrm{M}=\left(\left(\mathrm{I}_{\mathrm{HPTS}}+\mathrm{I}_{\mathrm{REF}} \cos \left(\phi_{\mathrm{REF}}\right)\right)^{2}+\left(\left(\mathrm{I}_{\mathrm{REF}} \sin \left(\phi_{\mathrm{REF}}\right)\right)^{2}\right)^{1 / 2}\right.
$$


and

i.e.

$$
\begin{aligned}
& \cot \left(\phi_{\mathrm{M}}\right)=\frac{\mathrm{I}_{\mathrm{HPTS}}+\mathrm{I}_{\mathrm{REF}} \cos \left(\phi_{\mathrm{REF}}\right)}{\mathrm{I}_{\mathrm{REF}} \sin \left(\phi_{\mathrm{REF}}\right)} \\
& \cot \left(\phi_{\mathrm{M}}\right)=\cot \left(\phi_{\mathrm{REF}}\right)+\frac{\mathrm{I}_{\mathrm{HPTS}}}{\mathrm{I}_{\mathrm{REF}}} \mathrm{x} \operatorname{cosec}\left(\phi_{\mathrm{REF}}\right)
\end{aligned}
$$

It also follows that

$$
\mathrm{I}_{\mathrm{L}}(\text { total })=\mathrm{I}_{\mathrm{B}}(\text { total })+M \sin \left(\omega \mathrm{t}+\left(\phi_{\mathrm{M}}\right)\right.
$$

i.e. the effect of adding the two varying luminescence intensities due to the reference and analyte lumophores is that the overall intensity variation with time appear phase shifted by $\phi_{\mathrm{M}}$ with respect to the frequency of the exciting light. In addition, the value of $\phi_{\mathrm{M}}$, which is one of the measurable quantities in phase modulation spectroscopy, is simply related to the amplitudes of the analyte (HPTS) and reference $\left(\mathrm{Ru}(\mathrm{dpp})_{3}{ }^{2+}\right)$, i.e. $\mathrm{I}_{\mathrm{HPTS}}$ and $I_{R E F}$, via eqn. (34). In this work the wavelength of the excitation light was selected so that only the anionic form of HPTS was excited. As a consequence, $\mathrm{I}_{\mathrm{HPTS}}$ will be proportional to $\left[\mathrm{Q}^{+} \mathrm{D}^{-} x \mathrm{H}_{2} \mathrm{O}\right]$ and, given eqn. (22), it follows that:

$$
\frac{\mathrm{I}_{\mathrm{HPTS}}^{o}-\mathrm{I}_{\mathrm{HPTS}}}{\mathrm{I}_{\mathrm{HPTS}}}=\alpha \mathrm{P}_{\mathrm{CO} 2}
$$

where $\mathrm{I}_{\mathrm{HPTS}}^{\mathrm{o}}$ is the value of the amplitude in the absence of carbon dioxide. Combining eqns. (35) and (37) it follows:

$$
\frac{\cot \left(\phi_{M}^{\mathrm{o}}\right)-\cot \left(\phi_{\mathrm{M}}\right)}{\cot \left(\phi_{\mathrm{M}}\right)-\cot \left(\phi_{\mathrm{REF}}\right)}=\alpha \mathrm{P}_{\mathrm{CO} 2}
$$

where $\phi_{\mathrm{M}}{ }^{0}$ is the observed phase angle when all the analyte dye is in its deprotonated form, i.e. no carbon dioxide present, and $\phi_{\mathrm{REF}}$ is the observed phase shift due to the reference alone, i.e. when all the analyte dye is in its protonated form, i.e. at infinite $\mathrm{P}_{\mathrm{CO} 2}$, at which point $\phi_{\mathrm{M}}$ will be at a minimum value.

Figure 16 illustrates the single and combined sine waves generated by the reference and analyte lumophores in (a) the absence and (b) the presence of carbon dioxide in the test phase for a DLR optical sensor for carbon dioxide, under interrogation by phase modulated fluorimetry. From this diagram it can be seen, as predicted by eqns. (36) and (38) that in the absence of carbon dioxide the signal due to the analyte dominates and the phase angle of the overall signal is nearer to that of the HPTS signal for which $\phi=0$, rather than that of the reference. In contrast, in the presence of a high level of carbon dioxide, the signal due to the reference dominates and the overall signal is nearer to that of the reference, for which $\phi=\phi_{\mathrm{REF}}$, than that of the analyte signal. Figure 17 illustrates a typical set of data reported by McCraith et $\mathrm{al}^{69}$ for their DLR carbon dioxide film 
comprising: a $\mathrm{Ru}(\mathrm{dpp})_{3}{ }^{2+}$ reference lumophore, encapsulated in nano-beads, with an HPTS $^{-}-\mathrm{CMTA}^{+}$analyte lumophore; all encapsulated in an organically modified silica. An analysis of the data illustrated in fig. 17 reveals a good fit to eqn.(38), using values for $\cot (\phi \mathrm{M} 0)$ and $\cot \left(\phi_{\mathrm{REF}}\right)$ of 3.84 and 1.45 , respectively.
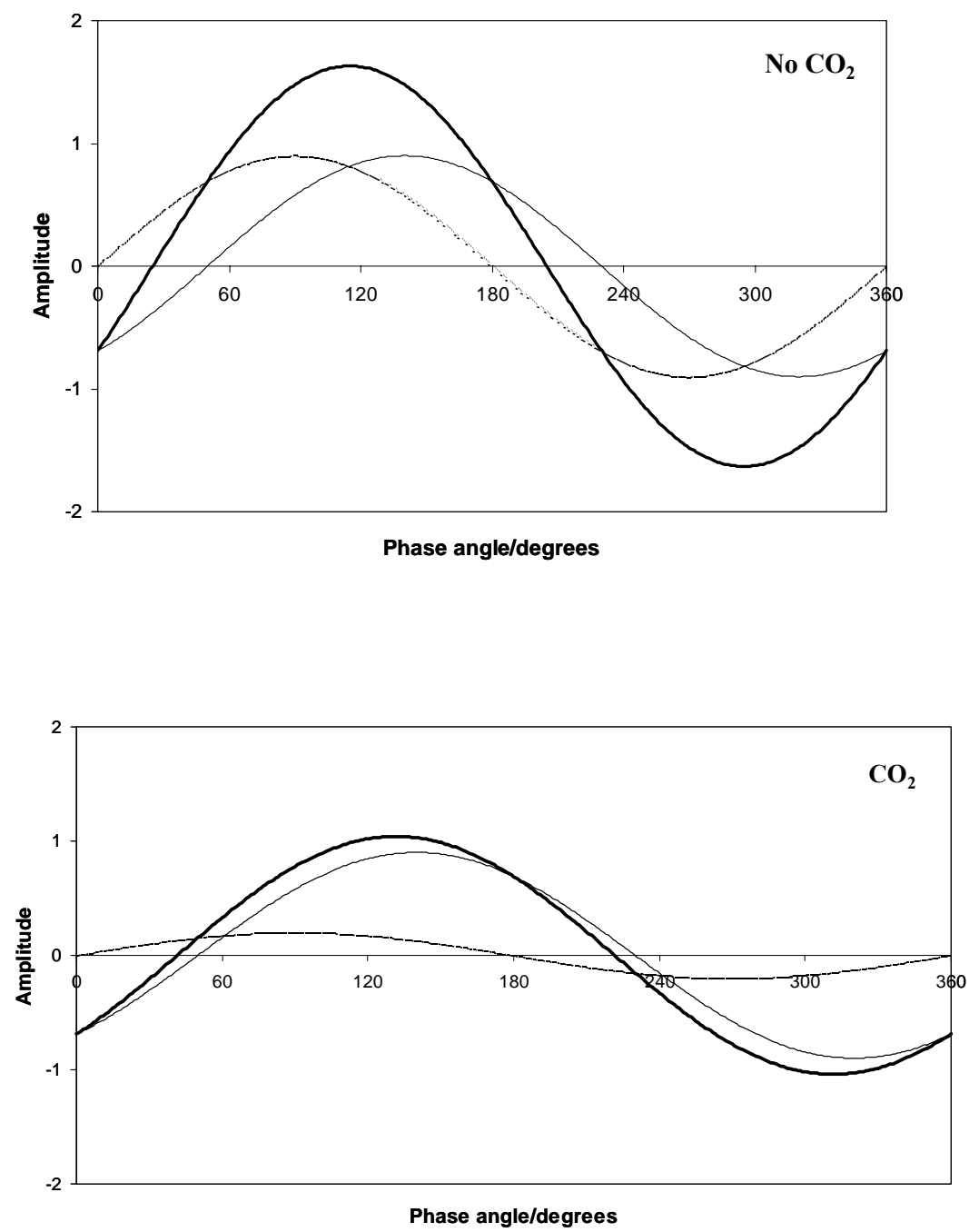

Figure 15. Single and combined sine waves of the luminescent intensity generated by a DLR sensor system subjected to a modulated excitation light in the absence and presence of carbon dioxide ${ }^{69}$. The analyte and reference single sine waves are depicted by the broken and solid lines. The overall, combined signal sine waves are denoted by the thickest solid lines. 


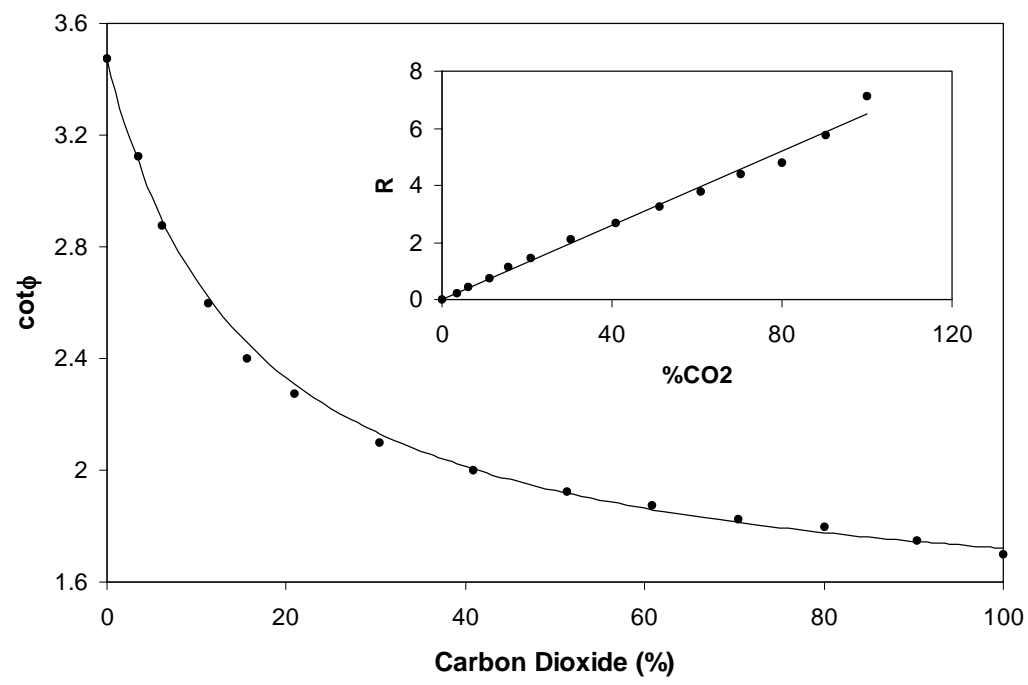

Figure 16. Plot of the observed variation in the contingent of the overall phase angle, $\cot \left(\phi_{\mathrm{M}}\right)$, for a $\mathrm{Ru}(\mathrm{dpp})_{3}{ }^{2+}$ nanobeads/HPTS-CMTA/silica DLR-based sensor as a function of $\mathrm{P}_{\mathrm{CO} 2}$. The insert diagram is a linearised form of the data in the main diagram, calculated using eqn. (38), using cot $\left(\phi_{\mathrm{M}}\right)$ and $\cot \left(\phi_{\mathrm{REF}}\right)=3.84$ and 1.45 , respectively ${ }^{69}$.

\section{APPLICATIONS AND PRACTICAL SYSTEMS}

This article began with a brief look at the possible areas of application of optical sensors for carbon dioxide. A number of studies, carried out using dry and wet luminescent optical sensors for carbon dioxide, have illustrated the efficacy of these indicators for the detection and measurement of carbon dioxide in: $b \operatorname{lood}^{24}$, food packages $^{69}$, bioreactors ${ }^{26,50}$ and seawater ${ }^{30}$. However, despite this success and promise, these sensors have been slow to take off as commercial products and the detection and analysis of carbon dioxide is still dominated by the Severinghaus electrode (dissolved work) and infrared spectroscopy (gaseous work). The reasons for this poor transition from research bench to market place are numerous but include: consumer resistance to new, and largely still unproven technology and, more seriously, basic concerns regarding the technology itself. Thus, as we have seen intensity-based measurements are fraught with several niggling and undermining problems, such as signal drift and dye bleaching, although many can be eliminated using a wavelength ratiometric method ${ }^{26}$ as we have seen. Lifetime-based measurements were very expensive and are still considered so for many who might otherwise readily adopt this technology, such as research laboratories, despite the recent notable inroads made by workers using long-lived donor lumophores ${ }^{66,68}$. All carbon dioxide optical sensors are also temperature sensitive, most markedly so, and many will exhibit some sensitivity to changes in humidity or osmotic pressure. Most optical sensors for dissolved carbon dioxide measurements require a gas-permeable membrane cover, to prevent dye-leaching and ion-exchange taking place, 
both of which can cause such sensors to fail. Despite the above technological concerns, there are one or two examples of apparent commercial success in the transfer of optical sensors for carbon dioxide technology from the laboratory to the market place. Thus, Yellow Springs Instrument (YSI) currently promote a wet, luminescence intensity-based carbon dioxide monitor that allows the precise, real-time measurement of dissolved carbon dioxide in situ ${ }^{70}$. Their YSI-8500 instrument has a range of $1-25 \% \mathrm{CO}_{2}$ and an accuracy of typically $\pm 5 \%$ of reading. Their sensor system exhibits only a $2 \%$ drift per week but, as you might expect given its wet nature, has a long $90 \%$ response time of $<7$ minutes with the recovery even longer, due to the hyperbolic response characteristics of such sensors. The sensor is not very bulky (12mm diameter with a 70-320 mm insertion depth) and utilises HPTS as the pH-sensitive lumophore. The YSI systems employs a ratiometric $^{26}$ analysis of the dye's fluorescence, exciting at two different wavelengths and monitoring the luminescence intensity at one, in order to minimise the various instrumental effects associated with such intensity-based measurements. Fig. 18 provides a schematic illustration of the sensor head for the YSI-8500, highlighting its major features. The system uses replaceable, disposable sensor capsules, thus promoting one of the attractive features of most optical sensors; the disposable nature of the transducer element.

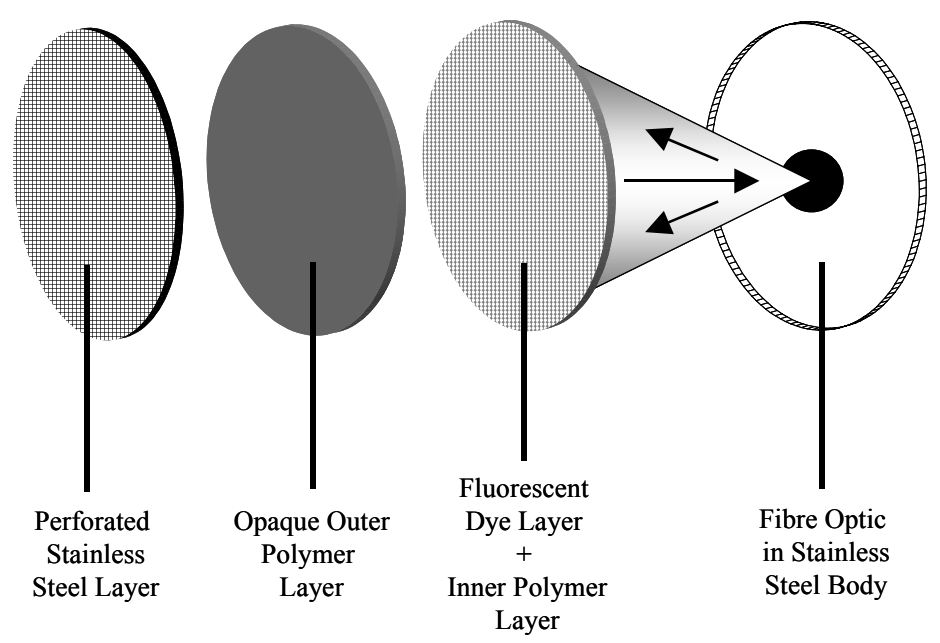

Figure 18. Schematic illustration ${ }^{70}$ of the sensor head of a YSI 8500 , wet optical sensor for carbon dioxide that is currently on the market.

Whereas YSI have opted for a wet, intensity-based optical sensor for carbon dioxide, OceanOptics, with their FCO2-R fibre optical sensor, have opted for a dry sensor which encapsulates the $\mathrm{pH}$-sensitive dye, HPTS, in a sol-gel medium, and is covered by a black silicone GPM coating ${ }^{71}$. The sensor has a dynamic range of $0-25 \% \mathrm{CO}_{2}$ and a resolution of at least $0.03 \%$. The instrumentation does not use a ratiometric technique (i.e. no two excitation sources) to interrogate the sensor film as employed by YSI, but instead monitors the whole luminescence spectral output using a miniature spectrophotometer. 
Like the YSI-8500, the FCO2-R uses a blue LED as the excitation source. The response time of the FCO2-R is typically 10 minutes and the probe itself is quite small $(1.6 \mathrm{~mm})$ diameter. However, as might be expected for a sol-gel based sensor, it must be stored in water at least 2 days before use and it is recommended to store it subsequently in water at all times after.

It is possibly surprising that there are no major lifetime-based optical sensors in the market, despite the fact that lifetime based optical sensors for oxygen already exist (e.g. OxySense $\left.^{\mathrm{TM}}\right)$. However, it is most likely that the higher cost of such technologically advanced systems is still proving a major barrier to its market transition. The recent move towards cheaper, lower frequency, diode-based phase modulated systems, whether they be FRET- or DLR-based, may eventually lead to a relatively inexpensive, commercially viable product that challenges and widens the market for small intensitybased optical sensors for carbon dioxide. However, for this to happen a great deal more research is necessary. It remains to be seen, therefore, what the commercial future of optical sensors for carbon dioxide is which is a slightly disappointing conclusion given its history of initial rapid development and the importance of the area of analysis to life, industry and the environment. 


\section{LIST OF TERMS AND SYMBOLS}

AcFl: Acryloly florescein

BMUB: $\beta$-methyl umbelliferon

BTB: Bromothymol blue

c-SNAFL: 5'and 6'-Carboxyseminaphtholfluorescein

c-SNARF: 5'and 6'-Carboxyseminaphtholrhodamine

CR: Cresol Red

$\mathrm{CTA}^{+}$: Hexadecyl trimethyl ammonium cation

CTAH: Hexadecyl trimethyl ammonium hydroxide

DLR: Dual lumophore referencing

DNPA: 2-(2,4-Dinitrophenylaxo)-1-naphthol-3,6disulphonic acid

EC: Ethyl cellulose

[Eu(tta) $\left.)_{3}\right]$ : tris(thenoyltrifluoroacetonato) europium (III)

Fl: Fluorescein

FRET: Fluorescence energy resonance transfer

GPM: gas-peremeable membrane

HCA: 7-hydroxycoumarin-4-acetic acid

HEMA: 2-Hydroxy methylmethacrylate

HPTS: 1, Hydroxypyrene-3,6,8-trisulphonic acid

MAPTAC: methacrylamidopropyl trimethyl ammonium chloride

MCP: meta-Cresol purple

NMA: 1-naphthylmetylamine

NR: Neutral red

NVP: Poly(N-vinylpyrrolidone)

PolyHEMA: poly(hydroxyethyl methacrylate)

PR: Phenol Red

PTA: Phase Transfer Agent

PVP: Poly(vinylpyrrolidone)

R6G: Rhodamine 6G

$\mathrm{Ru}\left(\mathrm{dph}\right.$-bpy) ${ }_{3}{ }^{2+}:$ Ruthenium(II) tris[4,4'-diphenyl-2,2'-bipyridyl] cation

$\mathrm{Ru}(\mathrm{dpp})_{3}{ }^{2+}$ : Ruthenium (II) tris(4,7-diphenyl-1,10-phenanthroline) cation

$\mathrm{Ru}(\mathrm{pzth})_{2}{ }^{2+}$ : Ruthenium(II) tris[2-(2-pyrazinyl)thiazole] cation

SRh: Sulforhodamine 101

TB: Thymol blue

TBAH: tetra butyl ammo1nium hydroxide

TBP: Tributyl phosphate

$\mathrm{TDMA}^{+}$: tridodecylmethylammonium cation

TMAH: Tetramethyl ammonium hydroxide

TMS : 3-Trimethylsilyl-1-propane sulphonate anion

THR: Texas Red hydrazine

TOAH: tetra octyl ammonium hydroxide 


\section{REFERENCES}

1. E. Rabinowitch. and Govindjee, Photosynthesis (Wiley, New York, 1969).

2. C.L. Lake, Clinical Monitoring (W.B. Saunders Co., Philadelphia, 1990).

3. J.S. Gravenstein, Gas Monitoring and Pulse Oximetry (Butterworth-Heinemann, Boston, 1990).

4. D.G. Mou, Process dynamics: instrumentation and control, Biotech. Adv., 1, 229-245 (1983).

5. M.L. Rooney, Active Food Packaging (Blackie Academic \& Professional, London, 1995)

6. R.P. Wayne, Chemistry of Atmospheres , $3^{\text {rd }}$ Edition, (Oxford University Press, Oxford, 2000).

7. J.W. Severinghaus and A.F. Bradley, Electrodes for blood $\mathrm{P}_{\mathrm{O} 2}$ and $\mathrm{P}_{\mathrm{CO} 2}$ determination, J. Appld, Physiol., 13, 515-520 (1958).

8. M.A. Jensen and G.A. Rechnitz, Reponse characteristics of the $\mathrm{pCO}_{2}$ electrode, Anal. Chem., 51, 19721977 (1979).

9. W.R. Seitz, Chemical sensors based on fibre-optics, Anal. Chem. 56, 16A-34A (1984).

10. Fiber Optical Chemical Sensors and Biosensors, volume 1, edited by O.S. Wolfbeis (CRC Press, Boca Raton, Florida, 1991),

11. Fiber Optical Chemical Sensors and Biosensors, volume 2, edited by O.S. Wolfbeis (CRC Press, Boca Raton, Florida, 1991),

12. G. Rao, S. B. Bambot, C.W. Kwong, H. Szmacinski, J. Sipior, R. Holavanahali and G. Carter, Application of fluorescence sensing to bioreactors, in:Topics in Fluorescence Spectroscopy, Volume 4: Probe Design and Chemical Sensing, edited by J.R. Lakowicz (Plenum,, New York, 1994), pp 417-448.

13. H.N. McMurray and J. Albadran, Colorimetric and fluorimetric polymer membrane gas-sensing materials, MRS Bulletin, 55-59 (1999).

14. O.S. Wolfbeis, Fibre-optic chemical sensors and biosensors, Anal. Chem., 72, 81R-89R (2000).

15. A. Mills and K. Eaton, Optical sensors for carbon dioxide: an overview of sensing strategies past and present, Quim. Anal., 19, 75-86 (2000).

16. O.S. Wolfbeis, Fibre-optic chemical sensors and biosensors, Anal. Chem., 74, 2663-2678 (2002).

17. D.W. Lübbers and N. Opitz, Die $p \mathrm{CO}_{2} / \mathrm{pO}_{2}$-Optode: Eine neue $p \mathrm{CO}_{2} / \mathrm{bzw} p \mathrm{O}_{2}$ meßsonde zur messung des $p \mathrm{CO}_{2}$ oder $\mathrm{pO}_{2}$ von gasen und flüssigkeiten, Naturforsch., 30c, 532-533 (1975)

18. D.W. Lübbers and N. Opitz, Blood gas analysis with fluorescent dyes as an example of their usefulness as quantitative chemical sensors, Anal. Chem. Symp. Ser., 17, 609-619 (1983).

19. D.W. Lübbers and N. Opitz, Quantitative fluorescence photometry with biological fluids and gases, Adv. Exp. Med. Biol., 75, 65-68 (1976).

20. N. Opitz and D.W. Lübbers, Compact $\mathrm{CO}_{2}$ gas analyser with favourable signal-to-noise ratio and resolution using special fluorescent sensors (optodes) illuminated by blue LED's, Adv. Exp. Med. Biol., 180, 757-762 (1983).

21. Z. Zhujun and W.R. Seitz, A carbon dioxide sensor based on fluorescence, Anal. Chim. Acta, 160, 305309 (1984).

22. J.A. Ferguson, B.G. Healey, K.S. Bronk, S.N. Barnard and D.R. Walt, Simultaneous monitoring of pH, $\mathrm{CO}_{2}$ and $\mathrm{O}_{2}$ using an optical imaging fibre, Anal. Chim. Acta, 340, 123-131 (1997).

23. O.S. Wolfbeis, L.J. Weis, M.J.P. Leiner and W.E. Ziegler, Fibre-optic fluorosensor for oxygen and carbon dioxide, Anal. Chem. 60, 2028-2030 (1988).

24. T. Hirschfeld, F. Miller, S. Thomas, H. Miller, F. Milanovich and R.W. Gaber, Laser-fibre-optic "optrode" for realtime in vivo blood carbon dioxide level monitoring, J. Lightwave Technol., L-5, 1027-1033 (1987).

25. C. Munkholm, D.R.Walt and F.P. Milanovich, A fibre-optic sensor for $\mathrm{CO}_{2}$ measurement, Talanta, 35, 109-112 (1988).

26. M. Uttamlal and D.R. Walt, A fibre-optic carbon dioxide sensor for fermentation monitoring, Biotechnol., 13, 597-601 (1995).

27. M.J.P. Leiner, Optical sensors for in vitro blood-gas analysis, Sensors and Actuators B, 29, 169-173 (1995).

28. M.J.P. Leiner, Luminescence chemical sensors for biomedical applications: scope and limitations, Anal. Chim. Acta, 255, 209-222 (1991)

29. J.W. Parker, O. Laksin, C. Yu, M-L. Lau, S. Klima, R. Fisher, I. Scott, and B.W. Atwater, Fibre-optic sensors for $\mathrm{pH}$ and carbon dioxide using a self-referencing dye, Anal. Chem., 65, 2329-2334 (1995).

30. M.B.Tabacco, M. Uttamlal, M. McAllister and D.R. Walt, An autonomous sensor and telemetry system for low-level $\mathrm{pCO}_{2}$ measurements in seawater, Anal. Chem., 71, 154-161, (1999).

31. D.R. Walt, G. Gabor, and C. Goyet, Multiple-indicator fibre-optic sensor for high-resolution $\mathrm{pCO}_{2}$ seawater measurements, Anal. Chim. Acta, 274, 47-52 (1993). 
32. J.R. Lakowicz, H. Szmacinski and M. Karakelle, High-stability non-invasive autoclavable naked optical $\mathrm{CO}_{2}$ sensor, Anal. Chim. Acta, 272, 179-186 (1993).

33. G. Orellana, N. C. Morino-Bondi, B. Segovia, and M.D. Marazuela, Fibre-optic sensing of carbon dioxide based on excited-state proton transfer to a luminescent ruthenium (II) complex, Anal. Chem. 64, 2210-2215 (1992).

34. M.D. Marazuela, N.C. Moreno-Bondi and G. Orellana, Enhanced performance of a fibre-optic luminescent $\mathrm{CO}_{2}$ sensor using carbonic anhydrase, Sensors and Actuators B, 29, 126-131 (1995).

35. M.D. Marazuela, M.C. Moreno-Bondi and G. Orellana, Luminescence lifetime quenching of ruthenium (II) polypyridyl dye for optical sensing of carbon dioxide, Applied Spectroscopy, 52, 1314-1320 (1998).

36. O.S. Wolfbeis, E. Fürlinger, H. Kroneis and H. Marsoner, Fluorimetric analysis: a study on fluorescent indicators for measuring near-neutral ("physiological") pH-values, Fresenius Z Anal. Chem., 314, 119-124 (1983).

37. A. Mills and Q. Chang, Fluorescence plastic thin-film sensor for carbon dioxide, Analyst, 118, 839-843 (1993).

38. A.Mills and Q. Chang, Modelled diffusion-controlled response and recovery behaviour of a naked optical film sensor with a hyperbolic-type response to analyte concentration, Analyst, 117, 1461-1466 (1992).

39. H. Szmacinski and J.R. Lakowicz, Lifetime-based sensing, in:Topics in Fluorescence Spectroscopy, Volume 4: Probe Design and Chemical Sensing, edited by J.R. Lakowicz (Plenum,, New York, 1994), pp 295-334.

40. A. Mills, Response characteristics of optical sensors for oxygen: models based on a distribution in $\tau_{\mathrm{o}}$ or $\mathrm{k}_{\mathrm{q}}$, Analyst, 124, 1301-1308 (1999).

41. A. Mills, Response characteristics of optical sensors for oxygen: model based on a distribution in $\tau_{\mathrm{o}}$ and $\mathrm{k}_{\mathrm{q}}$, Analyst, 124, 1309-1314 (1999).

42. P. Herman, Z. Murtaza and J.R. Lakowicz, Sensing of carbon dioxide by a decrease in photoinduced electron transfer quenching, Anal. Biochem., 272, 87-93 (1999).

43. D. B. Raemer, D.R. Walt and C. Munkholm, $\mathrm{CO}_{2}$ indicator for placement of tracheal tubes, US Patent No. 5,005,572 (1991).

44. A. Mills and Q. Chang, Carbon dioxide detector, US patent No. 5,480,611 (1996).

45. A.Mills, Q. Chang, and N. McMurray, Equilibrium studies on colorimetric plastic film sensors for carbon dioxide, Anal. Chem. 64, 1383-1389 (1992).

46. A.Mills, G. Chang, and N. McMurray, Equilibrium studies on colorimetric plastic film sensors for carbon dioxide, Anal. Chem. 64, 1383-1389 (1992).

47. B.H. Weigl and O.S. Wolfbeis, Sensitivity studies on optical carbon dioxide sensors based on ion pairing, Sensors and Actuators B, 28, 151-156 (1995).

48. A. Mills and L. Wild, Measurement of dissolved carbon dioxide using colourimetric polymer films, in: Proceedings of Medical Sensors and Fibre Optic Sensors and Delivery Systems volume 2631, edited by G. Orellana and M. A. Scheggi (SPIE , Barcelona, 1995), pp. 100-109.

49. A. Mills, A. Lepre and L. Wild, Breath-by-breath Measurement of Carbon Dioxide Using a Plastic Film Optical Sensor, Sensors and Actuators B, 38-39, 419-425 (1997).

50. Q. Chang, L. Randers-Eichhorn, J.R. Lakowicz and G. Rao, Steam-sterilisable fluorescence lifetime-based sensing film for dissolved carbon dioxide, Biotechnol. Prog. , 14, 326-331 (1998).

51. Y. Kawabata, T. Kamachika, T. Imasaka and N. Ishibashi, Fibre-optic sensor for carbon dioxide with a $\mathrm{pH}$ indicator dispersed in a poly(ethylene glycol) membrane, Anal. Chim. Acta, 219, 223-229 (1989)

52. A. Mills and Q. Chang, Carbon dioxide detector, US patent No. 5,480,611 (1996)

53. C. Munkholm, Method for activation of polyanionic fluorescent dyes in low dielectric media with quaternary onium compounds, U.S. Patent No. 5,387,525 (1995).

54. P. Müller and P.C. Hauser, Fluorescence optical sensor for low concentrations of dissolved carbon dioxide, Analyst, 121, 339-343 (1996).

55. O.S. Wolfbeis, B. Kovacs, K. Goswami and S.N. Klainer, Fibre-optic fluorescence carbon dioxide sensor for environmental monitoring, Mikrochim. Acta, 129, 181-188 (1998).

56. C. Malins and B. D. MacCraith, Dye-doped organically modified silica glass for fluorescence-based carbon dioxide gas detection, Analyst, 123, 23373-2376 (1998).

57. C. Malins, M. Niggermann and B.M. MacCraith, Multi- and light-optical chemical sensor employing a plastic substrate, Meas. Sci. Technol., 11, 1105-1110 (2000).

58. N. Nakamura and Y. Amao, Optical sensor for carbon dioxide combining colorimetric change of a $\mathrm{pH}$ indicator and a reference luminous dye, Anal. Bioanal. Chem., 376, 642-646 (2003).

59. N. Nakamura and Y. Amao, An optical sensor for $\mathrm{CO}_{2}$ using thymol blue and europium (III) complex composite film, Sensors and Actuators B, 92, 98-101 (2003). 
60. N. Nakamura and Y. Amao, Optical $\mathrm{CO}_{2}$ sensor for the combination of colorimetric change of $\mathrm{pH}$ indicator and internal reference luminous dye, Bull. Chem. Soc. Jpn., 76, 1459-1462 (2003).

61. K. Ertekin, I. Klimant, G. Neurauter and O.S. Wolfbeis, Characterisation of a reservoir-type capillary optical microsensor for $\mathrm{pCO}_{2}$ measurements, Talanta, 59, 261-267 (2003).

62. X. Ge, Y. Kostov and G. Rao, High-stability non-invasive autoclavable naked optical $\mathrm{CO}_{2}$ sensor, Biosensors and Bioelectronics, 18, 857-865 (2003).

63. D.A. Nivens, M.V. Schiza, S.N. Angel, Multilayer sol-gel membranes for optical sensing applications: single layer $\mathrm{pH}$ and dual layer $\mathrm{CO}_{2}$ and $\mathrm{NH}_{3}$ sensors, Talanta, 58, 543-550 (2002).

64. J. Sipior, S. Bambot, R.M. Smith, G.N. Carter, J.R. Lakowicz and G. Rao, A lifetime-based optical $\mathrm{CO}_{2}$ gas sensor with blue or red excitation and Stokes or anti-Stokes detection, Anal. Biochem., 227, 309318 (1995).

65. J. Sipior, L. Randers-Eichhorn, J.R. Lakowicz, G.M. Carter and G. Rao, Phase fluorimetric optical carbon dioxide gas sensor for fermentation off-gas monitoring, Biotechnol. Prog., 12, 266-271 (1996).

66. G. Neurauter, I. Klimant and O.S. Wolfbeis, Microsecond lifetime-based optical carbon dioxide sensor using luminescence resonance energy transfer, Anal. Chim. Acta, 382, 67-75 (1999).

67. G. Liebsch, I. Klimant, B. Frank, G. Holst, and O.S. Wolfbeis, Luminescence lifetime imaging of oxygen, $\mathrm{pH}$, and carbon dioxide distribution using optical sensing, Applied Spectroscopy, 54, 548-559 (2000).

68. C. Von Bültzingslöwen, A. K. McEvoy, C. McDonagh, and B.D. MacCraith, Lifetime-based optical sensor for high-level $\mathrm{pCO}_{2}$ detection employing fluorescence resonance energy transfer, Anal. Chim. Acta, 480, 275-283 (2003)

69. C. Von Bültzingslöwen, A.K. McEvoy, C. McDonagh, B.D. MacCraith, I. Klimat, C. Krause and O. Wolfbeis, Sol-gel based optical carbon dioxide sensor employing dual lumiphore referencing for applications in food packaging technology, Analyst, 127, 1478-1483 (2002).

70. www.ysi.com

71. www.OceanOpticsBV.com 